Article

\title{
Construction of a Single-Nucleotide Polymorphism Marker Based Quantitative Trait Loci Map and Validation of Resistance Loci to Bacterial Wilt (Ralstonia solanacearum) in Tomato
}

\author{
Il Sheob Shin ${ }^{1, *}$, Jung Ching Hsu ${ }^{2}$, Shu Mei Huang ${ }^{2}$, Jaw Rong Chen ${ }^{2}$, Jaw Fen Wang ${ }^{2}$, Peter \\ Hanson ${ }^{2}$ and Roland Schafleitner ${ }^{2, *}$ \\ 1 National Institute of Horticultural and Herbal Science, Rural Development Administration, 55365, Korea \\ Rep.; shinis3@korea.kr (IS Shin) \\ 2 The World Vegetable Center, PO Box 42, 74199, Taiwan; dew.hsu@worldveg.org (JC Hsu); shu- \\ mei.huang@worldveg.org (SM Huang); jaw-rong.chen@worldveg.org (JR Chen); jawfenwang@gmail.com \\ (JF Wang); peter.hanson@worldveg.org (P Hanson); roland.schafleiter@worldveg.org (R Schafleitner) \\ * Correspondence: roland.schafleitner@worldveg.org; Tel.: +886-(0)6-583-7801 (R Schafleitner); \\ shinis3@korea.kr; Tel.: +82-(10)-8775-3586 (IS Shin)
}

\begin{abstract}
Bacterial wilt (BW), caused by Ralstonia solanacearum is one of the major biotic factors limiting tomato production in the humid tropics. Pyramiding of resistance genes through marker-assisted selection is an efficient way to develop durable BW resistant cultivars. Tomato line 'Hawaii 7996' (H7996) is a stable and robust resistance source against various $R$. solanacearum strains. Major BW resistance quantitative trait loci (QTLs) Bwr12 and Bwr-6, and several minor or strain specific QTLs have been coarse-mapped in this line, but none has been fine-mapped and validated. The objective of the current study was to construct a high density genetic map using single-nucleotide polymorphism (SNP) markers derived from genotyping-by-sequencing, fine-map Bwr-12 and Bwr-6 and determine the effects of these QTLs using a near isogenic line (NIL) population. A high density genetic map using 1,604 SNP markers with an average distance of $0.82 \mathrm{cM}$ was developed for $188 \mathrm{~F} 9$ recombinant inbred lines derived from the cross H7996 $\times$ WVa700. A total of seven QTLs associated with BW resistance to race 1phylotype I or/and race 3-phylotype II strains were located on chromosomes 6 (Bwr-6.1, 6.2, 6.3 and 6.4) and 12 (Bwr-12.1, Bwr-12.2 and Bwr-12.3) with logarithm of odds (LOD) scores of 6.2-15.6 and 6.2-31.1, explaining 14.2$33.4 \%$ and $15.9-53.9 \%$ of the total phenotypic variation contributed from H7996, respectively. To validate the genetic effects of the two QTL regions, a set of $80 \mathrm{BC}_{3} \mathrm{~F}_{3}$ NILs containing different sections of Bwr-6 with or without Bwr-12 was phenotyped for disease severity after challenge with either race 1-phylotype I Pss4 or race 3-phylotype II Pss1632 BW strains over two seasons. Bwr-6.1 specific to Pss4 and Bwr-6.3 specific to Pss1632 were mapped to an interval of $5.0 \mathrm{cM}(P<0.05)$ between 6_33,444,000_SLM6-47 and 6_33,868,000_SLM6-124 SNP marker, and to $2.7 \mathrm{cM}(P<0.01)$ between positions 6_35,949,000_SLM6-107 to 6_36,750,000_SLM6-82 marker, respectively. In addition, the specific effect of Bwr-12 for resistance to Pss4 (LOD score of 5.8-16.1, $P<0.01$ ) was confirmed and markers for this QTL have already been made available previously.
\end{abstract}

Keywords: bacterial wilt; Ralstonia solanacearum; genotype-by-sequencing; disease resistance; quantitative trait loci; Solanum lycopersicum

\section{Introduction}

Bacterial wilt (BW) caused by the soil-borne bacterium Ralstonia solanacearum is a major limiting factor for tomato production in the humid tropics, leading to wilting and plant death [1-5]. The pathogen has a large host range encompassing more than 200 plant species, and is capable of reaching very high cell densities in the host xylem through rapid multiplication. $R$. solanacearum is reported to cause yield losses up to $91 \%$, dependent of the tomato cultivar, climate, soil type, cropping pattern, and strain [6-9]. Based on host range, biochemical properties, geographical origin, multilocus sequence analysis and partial sequencing of the endoglucanase gene, $R$. solanacearum has been 
delineated into five races, six biovars, four phylotypes, nine clades and 53 sequevars, respectively [2, 10-14]. Due to its broad genetic diversity, $R$. solanacearum was ranked second in a list of the top ten most scientifically and economically impactful plant bacteria [15]. Because the pathogen can survive in the soil without host plants for long periods it is difficult to control by agronomical practices or chemical treatments. The use of genetic resistance is considered to be the cheapest, most efficient and environmentally friendliest approach to control bacterial wilt, but breeding for durable resistance against $R$. solanacearum is challenging owing to the site-specific and strain-specific nature of resistance [16-22]. The complex interaction between host and BW strains causes an unstable host defense response. Several screening tests for resistant host plants have been conducted using phylotype I or/and phylotype II strains [5, 23-27] and various resistance sources were identified. Wang et al. [5] found that Hawaii 7996 (H7996, Solanum lycopersicum) demonstrated high levels of resistance on the basis of trials conducted in 11 countries in Asia, America and Australia. BW resistance quantitative trait loci (QTLs) in tomato have been mapped using various marker systems, such as simple sequence repeat (SSR), amplified fragment length polymorphic (AFLP), sequence characterized amplified region (SCAR), restriction fragment length polymorphism (RFLP), cleaved amplified polymorphic sequences (CAPS) markers [28-38] and were located on different chromosomes, depending on the resistance sources and pathogen strains. Two resistance QTLs derived from L285 against UW365 (biovar 2, race 3) strain were situated on chromosomes 6 and 10 [30]. F3 and F2:3 H7996 × West Virginia 700 (WVa700) populations inoculated by Pss4 (biovar 3, race 1-phylotype I), JT519 (biovar 3, race 1phylotype I), GMI8217 (biovar 1) and JT516 (biovar 2, race 3-phylotype II) showed that resistance factors were located on five chromosomes $(3,4,6,8$ and 12) [29, 33, 36]. Wang et al [37] identified two major BW resistance QTLs in H7996, Bwr-12 and Bwr-6, based on ten screening trials with an F9 recombinant inbred line (RIL) population derived from a cross between H7996 and the BW susceptible line WVa700; screening trials were conducted in the field or in the greenhouse and included phylotype I and phylotype II strains. Bwr-12 and Bwr-6 located in a 2.8 and $15.5 \mathrm{cM}$ interval on chromosome 12 and 6, respectively, controlled up to 56 and $22 \%$ of the phenotypic variation. These experiments also showed that Bwr-12 was effective for phylotype I, and Bwr-6 was associated with resistance to race 1-phylotype I and race 3-phylotype II strains [37]. These results showed that resistance to BW in tomato is a complex strain-specific trait and is controlled by multiple genes. Although several QTLs for resistance to R. solanacearum have been mapped, none of them was finemapped, hindering efficient marker-assisted selection and gene cloning. Availability of a high quality reference genome and improved marker technologies such as single nucleotide polymorphism (SNP) markers capable of high-throughput genotyping made fine mapping of QTLs in segregating populations easier and allow for efficient introgression of favorable alleles from a donor to a recipient by both positive and background selection [39-40]. Next-generation sequencing (NGS) technologies have facilitated the construction of reference genome sequences, which provide valuable information for understanding genomic variation and genome evolution [41]. NGS technologies also are used for genotyping. Genotyping by sequencing (GBS) is the most efficient tool for simultaneous genomewide SNP discovery and genotyping. GBS is simple, quick, and reproducible and SNP markers are obtained at relatively low cost in short time through multiplex sequencing of restriction siteassociated DNA [42]. The draw backs of the method are often large amounts of missing data due to low coverage sequencing [43-44] and uneven genome coverage, due to the sequence specificity of the chosen restriction enzyme [45]. GBS is used for genotyping for a wide range of purposes including for QTL mapping and genomic prediction in many crop and animal species, including for example rice [46], tomato [47-48], grape [49] and livestock species [50]. GBS can be successfully adapted to model species like tomato with well-characterized reference genomes, as well as to crops without reference genome sequences [51]. The software Tassel for GBS analysis is a very powerful pipeline to efficiently handle studies where up to hundreds of thousands or even millions of SNPs are generated from up to 100,000 individuals [52]. QTL validation is an essential step before using marker-assisted selection to introgress QTLs into new genetic backgrounds [53]. A large number of QTLs and molecular markers related with them have been identified and published, but only very few have been utilized in breeding programs. Failure to validate the QTLs and unexpected results in QTL introgression programs were mostly due to false positive QTLs, QTLs affected by environmental 
conditions, traits encoded by multiple genes, recombination between genes and the selectable markers, and epistatic effects with another QTL or with the genetic background [39, 54]. Near isogenic lines (NILs) have been used advantageously to identify and validate, as well as for fine mapping of QTLs. Moreover, NILs are highly useful to confirm that the QTL effect is indeed associated with the introgressed segments [55-57]. In this study, a high-density genetic map of a population derived from H7996 $\times$ WVa700 was constructed with more than 1000 SNP markers produced by GBS and markers flanking resistance genes to $R$. solanacearum were identified by QTL analysis. Furthermore, a NIL population containing different segments of Bw-6 was phenotyped over two seasons using two strains (Pss4 in phylotype I and Pss1632 in phylotype II) and genotyped with CAPS and SSR markers located in BW resistance QTL regions, specifically in Bw-6, to validate the effect of resistance alleles at main resistance QTL. A dense genetic map with markers flanking and within QTL regions will help to improve the efficiency to breed tomato resistant to BW.

\section{Results}

\section{Confirmation of Bwr-12 and Bwr-6 in H7996}

Table 1. Overview of GBS sequence data and alignment to the reference sequence

\begin{tabular}{llrr}
\hline & & \multicolumn{1}{c}{ Total } & Average/plant \\
\hline Raw data & Reads & $214,317,283$ & $1,127,986$ \\
& Bases $(\mathrm{Mb})$ & 21,646 & 114 \\
& & & \\
Filtered $^{\mathrm{a}}$ & Reads & $203,971,914$ & $1,073,536$ \\
& & & \\
Mapped $^{\mathrm{b}}$ & Reads & $187,279,899$ & 985,684 \\
& Tags (regions) & 333,914 & \\
Average depth $^{\text {Reads }}$ & Reads & 3.03 & \\
\hline
\end{tabular}

a The number of reads after filtering and removing barcodes

$\mathrm{b}$ The number of reads and tags mapped on reference genome of S_lycopersicum_chromosomes.2.40.fa

Table 2. Summary of GBS-SNPs mapped on the tomato genome.

\begin{tabular}{crrrrr}
\hline Chromosome & \multicolumn{1}{c}{ Start $(\mathrm{Mb})$} & \multicolumn{1}{c}{ End $(\mathrm{Mb})$} & SNPs & $\begin{array}{c}\text { Genetic } \\
\text { length }(\mathrm{cM})\end{array}$ & $\begin{array}{c}\text { Reference mapa } \\
(\mathrm{Mb})\end{array}$ \\
\hline C01 & 1.217 & 87.177 & 95 & 146.2 & 90.304 \\
C02 & 10.534 & 46.508 & 67 & 109.8 & 49.918 \\
C03 & 1.316 & 61.363 & 140 & 103.7 & 64.841 \\
C04 & 0.214 & 64.040 & 314 & 142.0 & 64.064 \\
C05 & 1.608 & 64.957 & 83 & 103.8 & 65.021 \\
C06 & 0.630 & 45.966 & $697(28)$ b & 111.5 & 46.042 \\
C07 & 1.669 & 62.696 & 101 & 97.8 & 65.269 \\
C08 & 1.118 & 62.418 & 117 & 105.0 & 63.033 \\
C09 & 0.070 & 67.609 & 71 & 127.1 & 67.662 \\
C10 & 0.203 & 63.324 & 142 & 112.9 & 64.834 \\
C11 & 0.070 & 52.523 & 412 & 74.5 & 53.386 \\
C12 & 0.179 & 62.072 & $78(23)$ & 87.7 & 65.486 \\
Total & & 740.653 & 2,317 & 1,322 & 759.861 \\
\hline
\end{tabular}

a The number of reads and bins mapped on reference genome of S_lycopersicum_chromosomes.2.40.fa

b No. of SSR markers that mapped on the physically identical position with SNPs are shown in the parentheses.

\section{GBS-SNP Identification}

A total of 214 million single-end (SE) reads comprising 21.6 Gbp sequence information were generated for 188 F9 RILs and the parents using the Illumina sequencing platform (Table 1). After removing low-quality reads and barcode sequences, about $95 \%$ of the sequence data, in average 1.1 million reads per plant sample were analyzed. In total $98 \%$ of the bases had a sequencing quality over 
Q30 and $91.87 \%$ of the filtered reads with 3.0 of average depth were successfully mapped to the reference genome 2.4. All genotyped markers were attributed to 12 linkage groups representing the 12 chromosomes of tomato, spanning $\sim 741 \mathrm{Mb}$ with an average distance of $0.32 \mathrm{Mb}$ between neighboring markers. The generated map covered $97.5 \%$ of the total physical distance of that the tomato reference genome (Table 2).

\section{SNPs-based Linkage Map}

Of the 2,951 polymorphic SNPs, 1,404 were used to develop a linkage map for the 188 RILs (Figure 1). The genetic map spanned $1,322 \mathrm{cM}$ with $0.94 \mathrm{cM}$ average genetic distance between two adjacent markers, suggesting that the marker density was sufficient to capture major genetic effects causing phenotypic variance for QTL analysis. However, gaps between markers of over $20 \mathrm{cM}$ length were found on chromosomes 1, 4, 5 and 10 and the greatest gap was $33.5 \mathrm{cM}$ from physical position 1.2 to $5.6 \mathrm{Mb}$ at a distal region of chromosome 1. Significant segregation distortion $(P<0.05)$ in the RIL population concerned $1,048(45.2 \%)$ markers. The segregation distortion rates (SDRs) varied from chromosome to chromosome. The highest significant SDR was in chromosome 11, where $-\log \mathrm{P}$ reached 24.7 (Figure 2).

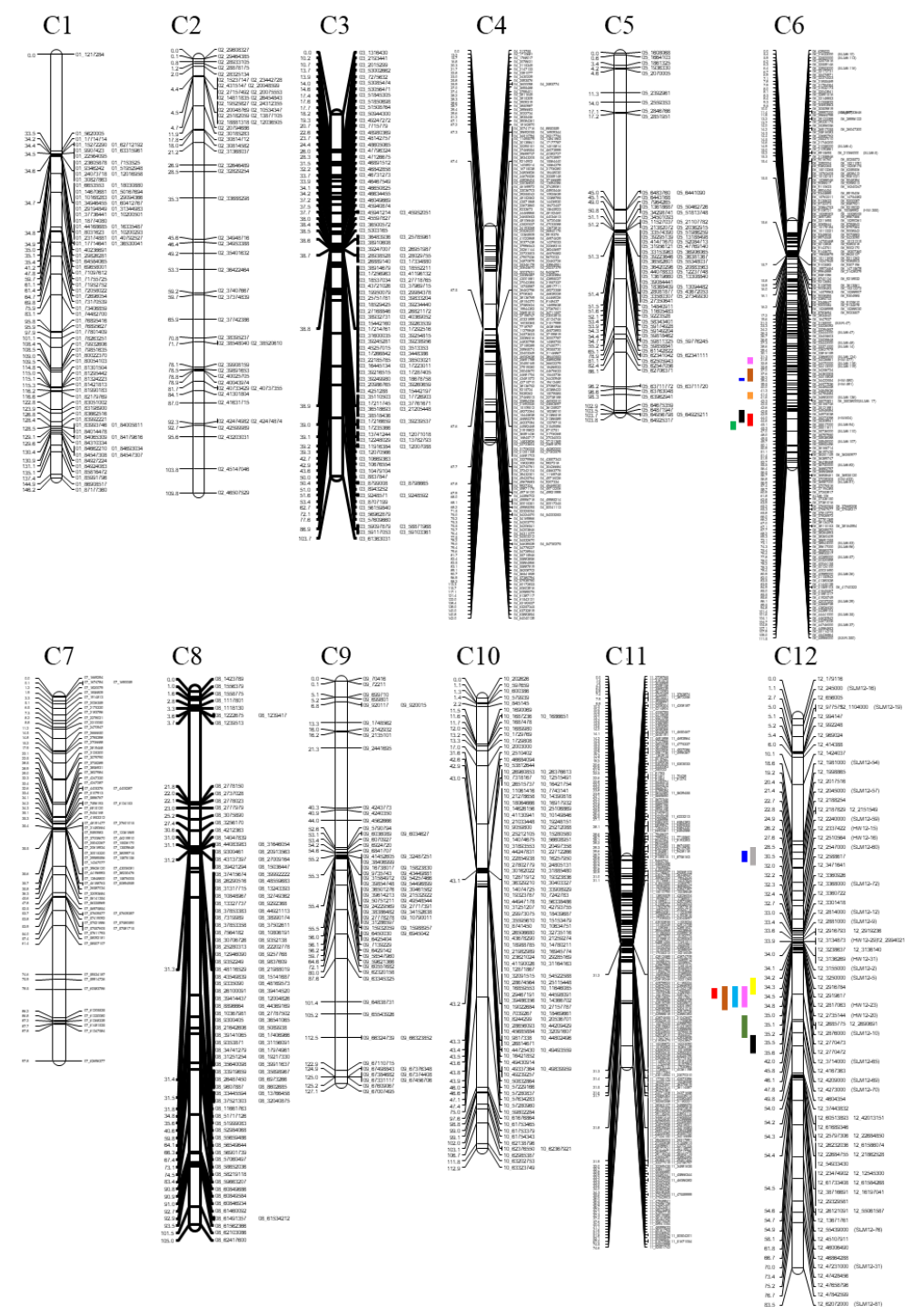

Figure 1. Genetic linkage map constructed using SNP markers including co-localized PCR-based markers (51 SSRs prefixed with SLM and 12 CAPS/dCAPS prefixed with HW). QTL regions identified in 10 individual trials named with ID-PW (Indonesia-Purwakarta), PH (the Philippines-UPLB)-Tm151, RE (Reunion-CIRAD)- JT516, RE (Reunion-CIRAD)-JT519, TH-CM (Thailand-Chiangmai), TW (Taiwan-WorldVeg)-Pss186, TW (TaiwanWorldVeg)-Pss4a (in greenhouse), TW (Taiwan-WorldVeg)-Pss4b (in screenhouse), TW (Taiwan- WorldVeg)- 
Pss4c (colonization test) and TW-TC (Taiwan-Taichung) are shown as blue, yellow, orange, red, green, pink, sky blue, brown, grey and black, respectively.

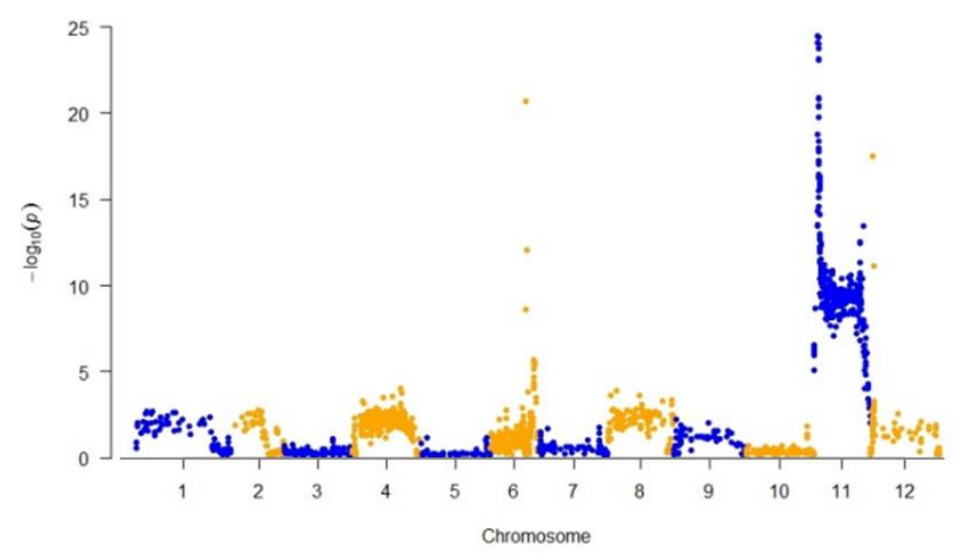

Figure 2. Manhattan plot of segregation distortion loci mapping of the F9 RIL mapping population.

\section{QTL Mapping and Detection of Epistatic Effects}

Seven significant QTL sites (four in chromosome 6 and three in chromosome 12) conferring resistance to bacterial wilt were contributed by 'H7996'. Combining the phenotypic data obtained in 10 trials with the SNP genotyping data, the reported QTLs associated with BW resistance in tomato were corroborated [37], one on chromosome 6, hereafter referred to as Bwr-6, and the other on 12, hereafter referred to as Bwr-12 (Figure 1). Four Bwr-6 with logarithm of odds (LOD) scores ranging from 6.2 to $15.6(P<0.01)$ that were detected with phenotypic data from seven independent trials were situated in 1.3 (Bwr-6.1), 2.5 (Bwr-6.2), 0.3 (Bwr-6.3) and $2.3 \mathrm{cM}$ (Bwr-6.4) intervals located at 31.3-32.5, 36.9-39.4 41.3-41.6 and 42.8-45.2 cM, respectively; the most significant Bwr-6.4 with 15.6 LOD score was located at $44.1 \mathrm{cM}$ and $\sim 35.3 \mathrm{Mb}$ (Figure 3). Of the four QTLs, Bwr-6.3 has been identified as a specific resistance site against phylotype II, the remaining were associated with defense to phylotype I strains. The phenotypic variation explained (PVE) of overall Bwr-6 ranged from $14.2 \%$ to $33.4 \%$ (Table 3). Similarly, Bwr-12 was consistently associated with resistance to phylotype I strains in all trials, but not to the phylotype II strain of trial RE-JT516 conducted by CIRAD on Reunion. This QTL with a LOD score ranging from 6.2 to 31.1 and a PVE of $15.9 \%$ to $53.9 \%$, was confirmed to be located at three sites of chromosome 12 at 28.5 to $31.9 \mathrm{cM}$ (Bwr-12.1), 34.2 to 34.9 $\mathrm{cM}(B w r-12.2)$ and 35.0 to $35.6 \mathrm{cM}$ (Bwr-12.3). Considering the highest LOD score on chromosome 12, the SNP marker associated with resistance to $R$. solancearum phylotype I strain was located at $\sim 34.5$ $\mathrm{cM}$ in Bwr-12.2 (the vicinity of physical position $\sim 2.9 \mathrm{Mb}$ ).

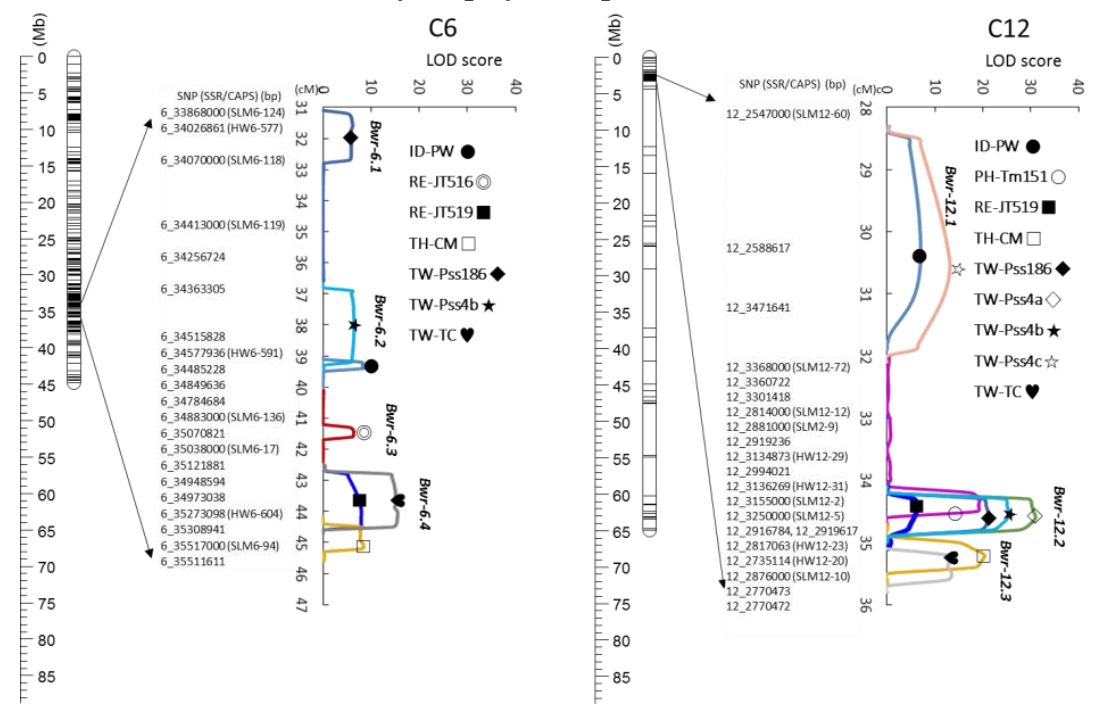


Figure 3. Mapping significant QTLs on chromosome 6 and 12 in an F9 RIL segregating tomato population. Marker names consist of chromosome number and physical position (bp) separated by an underscore and, if available, co-localized SSR or CAPS/dCAPS marker in parenthesis. A total of 16 QTL regions, seven for QTL-6 and nine for QTL-12 were identified in 10 trials. The trials are represented as different symbols in colors according to each trial. The left lateral axis shows genetic position $(\mathrm{cM})$ and upper axis shows the LOD score.

Table 3. Overview of resistance QTLs against $R$. solanacearum strains in 10 trials based on composite interval mapping (CIM) analysis of GBS-SNP markers mapped on reference genome of S_lycopersicum_ chromosomes.2.40.fa using Qgene.

\begin{tabular}{|c|c|c|c|c|c|c|}
\hline \multirow{2}{*}{$\begin{array}{c}\text { Linkage } \\
\text { group }\end{array}$} & \multirow{2}{*}{ Trial $^{\mathrm{a}}$} & \multicolumn{2}{|c|}{ Map position } & \multirow{2}{*}{$\mathrm{LOD}^{\mathrm{b}}$} & \multirow{2}{*}{$\begin{array}{l}\text { PVE } \\
(\%)^{c}\end{array}$} & \multirow{2}{*}{$\begin{array}{l}\text { Additive } \\
\text { effect }^{\mathrm{d}}\end{array}$} \\
\hline & & (bp) & $(\mathrm{cM})$ & & & \\
\hline \multirow[t]{8}{*}{6} & ID-PW & $34,577,936$ & 39.4 & 8.4 & 18.5 & 8.26 \\
\hline & RE-JT516 & $34,784,684-34,883,000$ & 41.5 & 6.4 & 24.0 & 7.25 \\
\hline & RE-JT519 & $35,273,098-35,308,941$ & 44.0 & 8.0 & 29.2 & 9.19 \\
\hline & TH-CM & $35,511,611-35,517,000$ & 45.1 & 8.5 & 18.8 & 9.69 \\
\hline & TW-Pss186 & $33,868,000-34,026,861$ & 31.6 & 6.2 & 14.2 & 5.37 \\
\hline & TW-Pss4b & $34,363,305-34,515,828$ & 38.2 & 6.5 & 14.7 & 6.53 \\
\hline & TW-TC & $35,273,098-35,308,941$ & 44.1 & 15.6 & 33.4 & 12.68 \\
\hline & 7 & $33,868,000-35,517,000$ & $31.6-45.1$ & $6.2-15.6$ & $14.2-33.4$ & 5.4- 12.7 \\
\hline \multirow[t]{10}{*}{12} & ID-PW & $2,547,000-2,588,617$ & 30.3 & 7.1 & 15.9 & 11.56 \\
\hline & PH-Tm151 & $2,916,784$ & 34.3 & 19.2 & 37.6 & 11.71 \\
\hline & RE-JT519 & $2,919,617$ & 34.5 & 6.2 & 23.3 & 8.10 \\
\hline & $\mathrm{TH}-\mathrm{CM}$ & $2,876,000$ & 35.2 & 20.4 & 39.3 & 16.79 \\
\hline & TW-Pss186 & $2,817,063-2,919,617$ & 34.6 & 21.5 & 40.9 & 11.40 \\
\hline & TW-Pss4a & $2,817,063-2,919,617$ & 34.6 & 31.1 & 53.9 & 14.38 \\
\hline & TW-Pss4b & $2,817,063-2,919,617$ & 34.6 & 25.3 & 46.2 & 14.82 \\
\hline & TW-Pss4c & $2,588,617$ & 30.5 & 13.2 & 35.0 & 12.64 \\
\hline & TW-TC & $2,770,473$ & 35.5 & 13.5 & 29.8 & 11.67 \\
\hline & 9 & $2,547,000-2,919,617$ & $30.3-35.5$ & $6.2-31.1$ & 15.9-53.9 & 8.1- 16.8 \\
\hline
\end{tabular}

a The same trial code and phenotype datasets as a previous study [37] (Wang et al. 2013) were applied to this analysis. All trials except RE-JT516 using phylotype II were infected by phylotype I.

b Maximum LOD score of the QTL, highly significant ( $P<0.01)$, except RE-JT516 on LG6 and RE-JT519 on LG12, significant $(P<0.05)$.

c Percentage of phenotypic variance explained (PVE) at the peak of QTL.

$d$ The positive values of additive effects indicated that the resistance alleles are introgressed from 'Hawaii 7996' (resistant parent).

By multiple QTL analysis using the R/qtl package, an additional QTL with a LOD score of 3.6 7.5 depending on interaction between QTL was found on chromosome 5 for only one trial (TW-Pss4b) (Table 4). Interactions between QTLs were tested to confirm epistatic effects of QTLs associated with BW resistance on chromosomes 5, 6 and 12. In seven trials more than two QTL regions were identified. In four trials (ID-PW, TW-Pss186, TW-Pss4b and TW-TC) significant interaction $(P<0.05)$ between Bwr-5, Bwr-6 and Bwr-12 was detected from using two versions (2.5 and 3.0) of the tomato reference genome.

Fine-mapping and Validation of BW Resistance QTLs in the NIL Population

To verify the phenotypic contribution of specific sections of $B w r-6$ and of $B w r-12$, a total of $80 \mathrm{BC}_{3} \mathrm{~F}_{3}$ NILs were developed from a cross between the BW resistant RIL 'NHG41' and the recurrent parent 'BL1413' through marker-assisted backcrossing. The NILs were homozygous for four different fragments of the original Bwr-6 interval reported by Wang et al., [37] and either carried the R or S allele at the QTL Bwr-12. The NIL population and the parental lines were inoculated with Pss4 
(phylotype I) and Pss1632 (phylotype II) strains in the spring and autumn season, and the percentage of wilted plants (W) was assessed four weeks after inoculation. The temperatures during the two seasons were significantly $\left(P<10^{-8}\right)$ cooler in spring (daily mean temperature of $17.7-24.7^{\circ} \mathrm{C}$ than in autumn 21.3-29.8 ${ }^{\circ} \mathrm{C}$ ). Over two seasons, the susceptible checks 'L390' and 'WVa700' were highly susceptible with 52-74\% W with Pss4 and 90\% W with Pss1632 in the spring, and 82-90\% W with Pss4 and $66-90 \% \mathrm{~W}$ with Pss1632 in the autumn (Table 5). High susceptibility of these lines indicated sufficient disease pressure in the experiments and increased wilting in autumn showed that elevated temperatures led to increased wilting. The W of resistant 'NHG41' inoculated with each strain did not show significant differences between trials with $16.2 \% \mathrm{~W}$ with Pss 4 and $26.9 \% \mathrm{~W}$ with Pss1632 in the spring, and $0.3 \% \mathrm{~W}$ with Pss4 and $16.2 \% \mathrm{~W}$ with Pss1632 in the autumn, respectively. In contrast, susceptible 'BL1413' displayed more severe symptoms in the autumn than in spring, except with Pss1632.

Table 4. Evaluation of epistatic effect of QTL associated with BW resistance from chromosome 5, 6 and 12 in F9 RIL population according model formula $\mathrm{Q} \sim \mathrm{Q} 1+\mathrm{Q} 2+\mathrm{Q} 1: \mathrm{Q} 2$ or $\mathrm{Q} \sim \mathrm{Q} 1+\mathrm{Q} 2+\mathrm{Q} 3+\mathrm{Q} 1: \mathrm{Q} 2+\mathrm{Q} 1: \mathrm{Q} 3+\mathrm{Q} 2: \mathrm{Q}$ of $\mathrm{R}$-software using reference genome of S_lycopersicum_chromosomes.3.0.

\begin{tabular}{|c|c|c|c|c|c|c|c|c|}
\hline Trial & $\begin{array}{c}\mathrm{CC} \\
\mathrm{a}\end{array}$ & $\begin{array}{l}\text { Degree of } \\
\text { freedom }\end{array}$ & $\begin{array}{l}\text { Sum of } \\
\text { square }\end{array}$ & LOD & $\%$ var & F value & $\begin{array}{c}P \text {-Value } \\
\left(x^{2}\right)\end{array}$ & $P$-Value (F) \\
\hline \multirow[t]{3}{*}{ ID-PW } & $\begin{array}{l}6: \\
12\end{array}$ & 4 & 3758 & 2.76 & 2.469 & 3.125 & 0.013 & $0.016^{* \mathrm{~b}}$ \\
\hline & 6 & & 17532 & 11.52 & 11.519 & 9.719 & 0.000 & $2.8 \mathrm{e}-09^{* * *}$ \\
\hline & 12 & & 71486 & 34.61 & 34.609 & 46.971 & 0.000 & $<2 \mathrm{e}-16^{* * *}$ \\
\hline \multirow[t]{3}{*}{ RE-JT519 } & $\begin{array}{l}6: \\
12\end{array}$ & 4 & 735 & 0.67 & 1.630 & 0.723 & 0.540 & 0.578 \\
\hline & 6 & & 7458 & 6.09 & 16.530 & 4.888 & 0.000 & $2.0 \mathrm{e}-04^{* * *}$ \\
\hline & 12 & & 6925 & 5.70 & 15.350 & 4.539 & 0.000 & $4.1 \mathrm{e}-04^{* * *}$ \\
\hline \multirow[t]{3}{*}{ TH-CM } & $\begin{array}{l}6: \\
12\end{array}$ & 4 & 2510 & 1.33 & 1.585 & 1.488 & 0.188 & 0.208 \\
\hline & 6 & & 21783 & 10.36 & 13.752 & 8.609 & 0.000 & $3.1 \mathrm{e}-08^{* * *}$ \\
\hline & 12 & & 54652 & 22.28 & 34.505 & 21.600 & 0.000 & $<2 \mathrm{e}-16^{* * *}$ \\
\hline \multirow[t]{3}{*}{ TW-Pss186 } & $\begin{array}{l}6: \\
12\end{array}$ & 4 & 2487 & 2.98 & 3.998 & 3.388 & 0.008 & $0.011^{*}$ \\
\hline & 6 & & 7052 & 7.94 & 11.34 & 6.404 & 0.000 & $3.9 \mathrm{e}-06^{* * *}$ \\
\hline & 12 & & 21418 & 20.53 & 34.44 & 19.45 & 0.000 & $<2 \mathrm{e}-16^{* * *}$ \\
\hline \multirow[t]{9}{*}{ TW-Pss4b } & $\begin{array}{c}5: \\
6\end{array}$ & 4 & 4894 & 2.85 & 5.177 & 3.237 & 0.011 & $0.014^{*}$ \\
\hline & 5 & & 13579 & 7.47 & 14.364 & 5.989 & 0.000 & $9.9 \mathrm{e}-06^{* * *}$ \\
\hline & 6 & & 16765 & 9.04 & 17.734 & 7.394 & 0.000 & $4.3 \mathrm{e}-07^{* * *}$ \\
\hline & $\begin{array}{l}5: \\
12\end{array}$ & 4 & 226 & 0.19 & 0.239 & 0.211 & 0.927 & 0.932 \\
\hline & 5 & & 4483 & 3.64 & 4.743 & 2.785 & 0.000 & $0.013^{*}$ \\
\hline & 12 & & 36611 & 23.18 & 38.727 & 22.746 & 0.000 & $<2 \mathrm{e}-16^{* * *}$ \\
\hline & $\begin{array}{l}6: \\
12\end{array}$ & 4 & 2706 & 2.42 & 2.863 & 2.739 & 0.025 & $0.030^{*}$ \\
\hline & 6 & & 8326 & 7.05 & 8.807 & 5.617 & 0.000 & $2.3 e-05^{* * *}$ \\
\hline & 12 & & 37267 & 25.01 & 39.421 & 25.143 & 0.000 & $<2 \mathrm{e}-16^{* * *}$ \\
\hline \multirow[t]{3}{*}{ TW-Pss4c } & $\begin{array}{l}6: \\
12\end{array}$ & 4 & 1332 & 1.03 & 1.946 & 1.124 & 0.317 & 0.348 \\
\hline & 6 & & 7332 & 5.27 & 10.714 & 4.128 & 0.000 & $7.8 \mathrm{e}-4^{* * *}$ \\
\hline & 12 & & 19788 & 12.57 & 28.915 & 11.140 & 0.000 & $4.6 \mathrm{e}-10^{* * *}$ \\
\hline TW-TC & $\begin{array}{l}6: \\
12\end{array}$ & 4 & 3135 & 2.21 & 2.784 & 2.484 & 0.038 & $0.046^{*}$ \\
\hline
\end{tabular}




\begin{tabular}{cllllll}
6 & 27757 & 16.20 & 24.646 & 14.663 & 0.000 & $1.9 \mathrm{e}-13^{* * *}$ \\
12 & 26319 & 15.51 & 23.368 & 13.903 & 0.000 & $8.0 \mathrm{e}-13^{* * *}$ \\
\hline
\end{tabular}

a Chromosome combination for evaluation of epistatic effect between two QTLs.

b Significance at $P<0.05, P<0.01$ and $P<0.001$ is indicated by ${ }^{*}{ }^{* *}$ and ${ }^{* * *}$, respectively.

Table 5. Descriptive statistics of percentage of wilted plants of the NIL population, parents (NHG41 resistant donor; BL1413, susceptible recipient), and resistant (H7996) and susceptible control (WVa700 and L390) for resistance to $R$. solanacearum Pss4 and Pss1632 strains according to season (spring and autumn). The differences between the mean values of $\mathrm{W}$ were evaluated using Duncan's multiple range tests, and $P<0.05$ was considered a significant difference. Prepositive capital letters and postpositive small ones of percentage of wilted plant displayed differences between values within the same row and within the same column, respectively.

\begin{tabular}{llrrrr}
\hline \multirow{2}{*}{ Plant } & \multirow{2}{*}{ Variables } & \multicolumn{2}{c}{ Pss4 } & \multicolumn{2}{c}{ Pss1632 } \\
\cline { 3 - 6 } NIL & Mean & Spring & Autumn & Autumn \\
& Minimum & D 21.4cd & A 80.6ab & C 57.4 b & B 77.5 a \\
& Median & 0.3 & 26.9 & 26.4 & 54.8 \\
& Maximum & 23.2 & 89.7 & 58.5 & 79.9 \\
& Standard deviation & 62.2 & 89.7 & 89.7 & 89.7 \\
NHG41 & Mean & 17.3 & 14.1 & 13.4 & 10.0 \\
BL1413 & Mean & A $16.2 \mathrm{~d}$ & A $0.3 \mathrm{c}$ & A 26.9 c & A 16.2 b \\
H7996 & Mean & B 38.0bc & A 81.7ab & A 78.0ab & A 81.7 a \\
WVa700 & Mean & $0.3 \mathrm{~d}$ & $0.3 \mathrm{c}$ & $38.0 \mathrm{bc}$ & $0.3 \mathrm{~b}$ \\
L390 & Mean & $73.8 \mathrm{a}$ & $81.7 \mathrm{ab}$ & $89.7 \mathrm{a}$ & $66.4 \mathrm{a}$ \\
\hline
\end{tabular}

The NIL population inoculated with Pss1632 showed a continuous distribution of resistance. W through Pss1632 inoculation during the spring trial was nearly normal distributed among NILs, whereas during the autumn season, the disease symptoms were skewed towards susceptibility. In the Pss4 trial, $\mathrm{W}$ in spring was skewed towards the resistant parent, whereas disease incidence in the autumn season was skewed towards the susceptible parent. Distributions showed that disease incidence $(\mathrm{W})$ was significantly $(P<0.01)$ higher in the hot season (autumn) than in the cooler season (spring) (Figure 4). Also the virulence of race 3-phylotype II Pss1632 strain was significantly $(P<0.01)$ greater in autumn (mean temperature: $21-30^{\circ} \mathrm{C}$ ) than in spring (mean temperature: $18-25^{\circ} \mathrm{C}$ ), similar to that reported using 45 race 3-phylotype II stains isolated in Taiwan by Lin et al. [58].

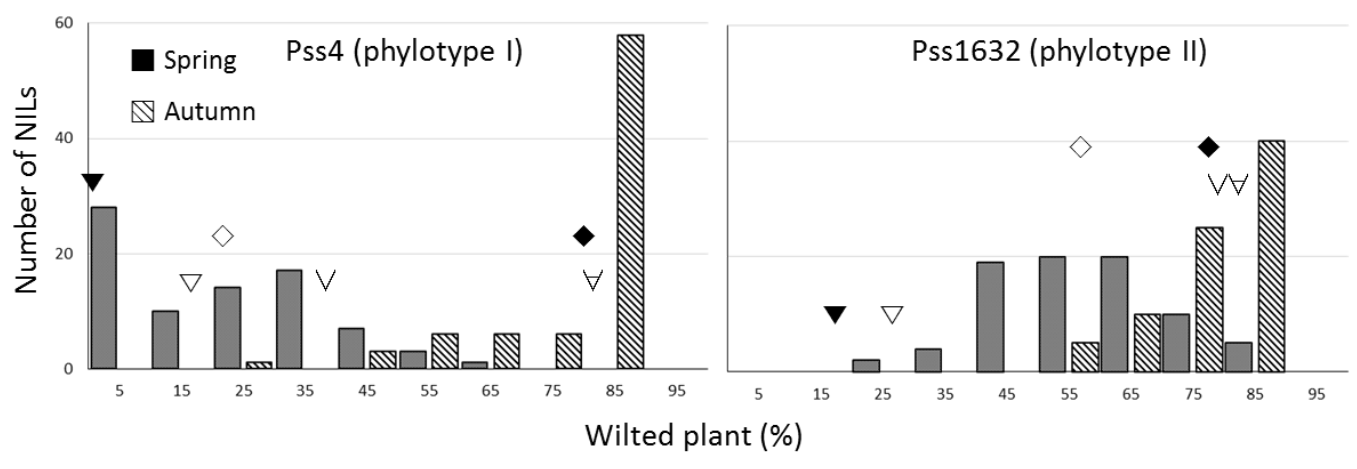

Figure 4. Frequency distribution of percentage of wilted plant of the 80 NILs for resistance to $R$. solanacearum Pss4 and Pss1632 strains according to season (spring and autumn). Mean values of the donor parent (NHG41), the recipient parent (BL1413) and NIL population are shown as $\nabla, \quad \vee$ and $\diamond$ for the spring trial and $\boldsymbol{\nabla}, \forall$ and for the autumn trials, respectively.

The variance components of the genotype $\times$ season and genotype $\times$ strain interaction were significant at $P<0.001$ for $\mathrm{W}$ and, consequently, data from each of the two seasons and two strains 
were separated for QTL validation. Broad sense heritability estimates of the disease incidence for the Pss4 strain were higher, i.e., 0.61 in spring and 0.63 in autumn than 0.32 and 0.20 for Pss1632, respectively, which indicated that most of the phenotypic variation of resistance to Pss1632 strain observed resulted from environmental factors such as temperature. The Pearson correlation coefficients between trials were significant for season and pathogen strain combination analyzed in the $\mathrm{BC}_{3} \mathrm{~F}_{3}$ NIL population (Table 6). Within Pss4 inoculation, spring and autumn trials were significantly correlated with each other $\left(R^{2}=0.58, P<0.0001\right)$, while there was no significant correlation $(P<0.076)$ in Pss1632 inoculation across seasons, which confirmed that phenotypic data for validation of QTL effect should be treated separately for each season and stain, as the responses to these factors probably rely on different genetic loci.

Table 6. Phenotypic correlation coefficients among percentage wilted plants and pathogen strains estimated in the $\mathrm{BC}_{3} \mathrm{~F}_{3}$ NIL population. Correlation coefficient values and $P$-values were represented with italic letters and plain letters, respectively.

\begin{tabular}{ccrrrr}
\hline \multirow{2}{*}{$\begin{array}{c}\text { Strain } \\
\left(\mathrm{W}^{\mathrm{a}}\right)\end{array}$} & \multirow{2}{*}{ Season } & \multicolumn{2}{c}{ Pss4 } & \multicolumn{2}{c}{ Pss1632 } \\
\cline { 3 - 6 } Pss4 & 1st & \multicolumn{1}{c}{ Spring } & Autumn & Spring & \multicolumn{1}{c}{ Autumn } \\
& 2nd & $2.13 \mathrm{E}-08$ & 0.58 & 0.36 & 0.18 \\
Pss1632 & 1st & 0.00100 & 0.08359 & 0.19 & 0.33 \\
& 2nd & 0.10310 & 0.00269 & 1 & 0.20 \\
& & &
\end{tabular}

a Percentage of wilted plants (W) was used for disease assessment methods to record disease incidence of plants after inoculation with $R$. solanancerum race 1-phylotype I strain Pss4 and race 3-phylotype II strain Pss1632.

${ }^{b}$ Disease incidence was assessed over two season: cool spring and hot autumn.

To explore whether the selected markers from Bwr-6 and Bwr-12 were associated with disease resistance, a single marker analysis was conducted with 34 PCR-based markers flanking the Bwr-6 (17: 12 SSR and 5 CAPS) and Bwr-12 (17: 11 SSR and 6 CAPS) loci and phenotyping data of W against race 1-phylotype I strain Pss4 and race 3-phylotype II strain Pss1632 over two seasons. A total of 16 markers located in the Bwr-12 region were confirmed over two seasons. They were significantly related with BW resistance against Pss4, but not Pss1632. Bwr-12.2 was located in a $0.6 \mathrm{cM}$ interval between SNP12-3250000 (34.2 cM) and SNP12-2770472 (34.8 cM) in the F9 RIL population. However, the QTL region controlling BW caused by Pss4 (LOD score > 10; phenotypic variation explained > $47.5 \%$ ) was extended to a $9.7 \mathrm{cM}$ segment ranging from HW12-72 CAPS (32.3 cM) to SLM12-65 SSR $(42.0 \mathrm{cM})$ (Figure 5). In contrast to Bwr-12, Bwr-6 had low LOD scores of 3.9 and 2.3 and it was estimated that the resistance gene located in this region reduces BW incidence of Pss1632 and Pss4 in hotter condition, respectively. The effect of this QTL could be delimited to markers SLM6-110 and SLM6-107 spanning over $2.7 \mathrm{cM}$.

\section{Discussion}

Several QTL mapping studies have been performed to understand the genetic nature of BW resistance in tomato [29-31, 33-34, 36-38]. QTLs around Bwr-6 and Bwr-12 have been detected in several studies and resulted in design of markers for selection in breeding. Marker-assisted selection for Bwr-12 and Bwr-6 is widely practiced in tomato breeding programs. However, QTL intervals were relatively large, especially for Bwr-6, and knowledge of the precise locations of these QTLs would lead to better marker, and reduction of linkage drag from the donor parent. Information of the specificity of resistance loci to different pathogen strains and their activity under different climatic condition would facilitate pyramiding the most promising QTLs in breeding. The current study used high density genetic and physical maps and phenotyping data from multilocation BW screening of the HW RIL population to fine-map Bwr-6 and Bwr-12, and then to confirm and validate the resistance loci in a NIL population.

A GBS approach resulted in over 10,000 polymorphic SNP markers that were ordered along the chromosomes of a reference sequence [44]. In this study, over $87 \%$ of the produced reads could be aligned to the tomato reference genome (S_lycopersicum_chromosomes.2.40.fa). On the basis of 
stringent selection criteria including missing data percentage, minor allele frequency and percent heterozygosity for filtering SNPs, a panel of robust SNPs comprising about $19 \%$ of the 12,654 SNPs called by comparison of the $S$. lycopersicum genome sequences was used for constructing a genetic map. In spite of the dramatic reduction in marker number, a sufficient number of SNP markers $(2,317$ SNPs) remained available for QTL mapping. The GBS approach of this work facilitated the construction of SNP-based physical and genetic maps of sufficient resolution for QTL mapping. A total of 1,404 SNPs (11\%) were finally used for constructing a dense genetic map for the F9 RIL population. Polymorphic SNPs with below 3.0 LOD score or showing high SDR or low crossover rate that especially situated in chromosome 6 and 11 was excluded to construct precise genetic map. The current dense map will be useful for the development of high-density consensus maps and finemapping of QTL.

QTL-6

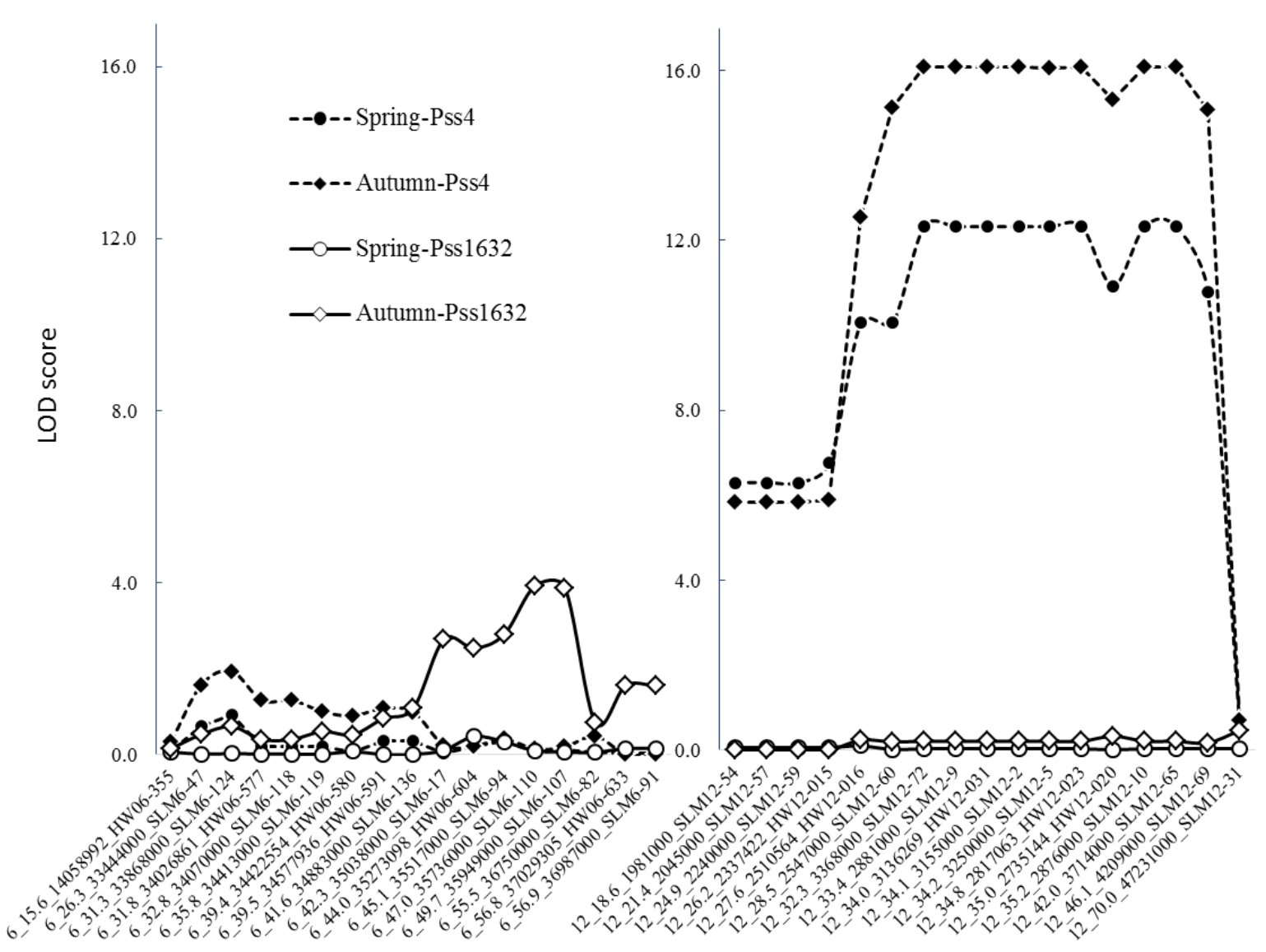

Figure 5. Single marker analysis for flanking markers situated on QTL-6 and QTL-12 region identified from F9 RIL population based on percentage of wilted plant $(W)$ in plants challenged with race 1-phylotype I strain Pss4 and race 3-phylotype II strain Pss1632 over two seasons in the $\mathrm{BC}_{3} \mathrm{~F}_{3}$ NIL population. Trial code consists of two parts, first the season (1st = spring or 2 nd = autumn) followed by strain name (Pss4 or Pss1632). Y-axis shows the LOD score and $\mathrm{X}$-axis shows the marker labels. Each marker is named as A_B_C_D, with 'A' being the chromosome number, ' $\mathrm{B}$ ' the genetic position, ' $\mathrm{C}$ ' the physical position, and ' $\mathrm{D}$ ' co-localized SSR or CAPS/dCAPS marker with SNP.

Based on field and greenhouse evaluations conducted worldwide, 'H7996' was identified as a promising breeding resource with stable resistance to $R$. solanacearum [5, 37]. QTL mapping using Qgene 4.0 with reference genome of S_lycopersicum_chromosome.2.4 version in a 188 F9 RIL population developed from a cross between 'H7996' and 'WVa 700' revealed two QTLs for BW resistance, one major QTL on chromosome 12 important for resistance to phylotype I isolates, and another QTL on chromosome 6 associated with resistance to both phylotype I and phylotype II 
isolates. These results corroborated findings of previous H7996 mapping studies [29, 36-37] except in this study the Bwr-12 region in trials PH-Tm151 and ID-PW were shifted toward the distal end of a $2.9 \mathrm{cM}$ interval around SLM12-2 SSR marker located at the end of QTL region. Bwr-6.3 identified from JT-516 strain, the only race 3-phylotype II strain among the 10 trials provided little resistance (LOD 6.4, $P<0.05$ ) compared with the finding of Wang et al. [37]. Bwr-12 with a LOD score ranging from 7.1 to 31.1 and a PVE from $15.9 \%$ to $53.9 \%$, respectively, provided strong and stable BW resistance to race 1-phylotype I strains, while a race 3-phylotype II isolate was affected by the only Bwr-6. Additional HW RIL phenotyping trials with phylotypes II, III, and IV would advance progress towards fine-mapping BW resistance. Several studies reported additional QTLs on chromosome 3, 4, 8,10 and 11 connected with BW resistance $[29,33,36]$ in the same HW mapping population but these QTLs were not detected in this study. Additional multi QTL analysis by R/qtl package with a new SNP set however revealed significant $(P<0.05)$ new QTL regions on chromosome 5 in trial TW-Pss $4 \mathrm{~b}$ (Table 4). In addition, this analysis confirmed a significant QTL epistasis $(P<0.05)$ between Bwr-5 and Bwr-6 at TW-Pss4b, and between Bwr-6 and Bwr-12 at ID-PW, TW-Pss186, TW-Pss4b, and TWTC. QTLs identified in the ten trials were considered major when PVE was greater than $10 \%$. The genetic effect of all QTLs was lower than the broad-sense heritability for disease resistance (0.64-0.94, Table 7), therefore we assume that additional minor QTLs contributed to resistance against race 3phylotype II strains. Whole genome re-sequencing of RILs and read assembly could help detecting minor QTLs and elucidate their interaction with other QTLs. 'H7996' is not resistant to all $R$. solanacearum isolates and was susceptible to R. solanacearum UW551, a typical sequevar 1 (Race 3 biovar 2) strain [59] that causes losses in temperate zones and tropical highlands. This isolate killed about $80 \%$ of $\mathrm{H7996}$ plants within 14 days post inoculation [60]. Therefore, exploitation of new breeding sources especially against race 3-phylotype II is required to develop multi-phylotype resistance tomato cultivars.

Table 7. Estimates of phenotypic variation (PV), coefficient of variation (CV), genotypic and phenotypic coefficients of variation (GCV and PCV), broad-sense heritability $\left(\mathrm{H}^{2}\right)$, and genetic advance (GA) for bacterial wilt incidence in RIL population evaluated in various environments.

\begin{tabular}{crrrrrrr}
\hline Trial & \multicolumn{1}{c}{ PV } & \multicolumn{1}{c}{ CV } & \multicolumn{1}{c}{ GCV } & \multicolumn{1}{c}{ PCV } & \multicolumn{1}{c}{$\mathrm{H}^{2}$} & \multicolumn{1}{c}{ GA } & GA(\%, mean) \\
\hline ID-PW & 1264.80 & 53.27 & 50.89 & 15.99 & 0.91 & 66.78 & 100.15 \\
PH-Tm151 & 899.10 & 44.17 & 35.42 & 26.48 & 0.64 & 39.68 & 58.52 \\
RE-JT516 & 364.09 & 25.94 & 24.39 & 8.99 & 0.88 & 34.65 & 47.21 \\
RE-JT519 & 546.14 & 124.32 & 120.91 & 30.07 & 0.94 & 45.40 & 242.06 \\
TH-CM & 1407.50 & 90.84 & 80.04 & 43.16 & 0.77 & 59.96 & 145.33 \\
TW-Pss186 & 726.10 & 47.44 & 39.29 & 26.67 & 0.68 & 38.06 & 67.06 \\
TW-Pss4a & 601.10 & 30.45 & 25.60 & 16.53 & 0.71 & 35.69 & 44.37 \\
TW-Pss4b & 872.90 & 41.90 & 36.66 & 20.39 & 0.76 & 46.55 & 66.09 \\
TW-Pss4c & 899.70 & 57.53 & 52.77 & 23.19 & 0.84 & 51.87 & 99.67 \\
TW-TC & 1260.50 & 84.90 & 79.53 & 30.13 & 0.87 & 64.05 & 153.43 \\
\hline
\end{tabular}

BW susceptibility bio assays on $80 \mathrm{BC}_{3} \mathrm{~F}_{3}$ NILs, parents and resistant/susceptible controls with race 1-phylotype I Pss4 and race 3-phylotype II Pss1632 strains over two seasons, confirmed the resistance phenotype of the NILs against two strains under two temperature regimes, the cooler spring season and the warmer autumn season. Mean values of NILs, the susceptible parent and controls showed different sensitivity patterns depending of the bacterial strain and season. Under higher temperatures $\left(21-30^{\circ} \mathrm{C}\right)$ the plant defense response against BW seems to be lower [61-62], while Pss4 and Pss1632 or other tropical strains such as of K60 and GMI1000 have reduced virulence in cooler conditions (18$\left.25^{\circ} \mathrm{C}\right)[3,63-64]$. Consequently, the percentage of wilted NILs was significantly higher in the relative warm conditions of the autumn trial than in the cool spring trial. Carmeille et al. [29] reported 
contrasting results that wilting symptoms in tomato were more severe during the cool season after inoculation with the race 3-phylotype II JT-516 stain

The broad heritability estimate of resistance in the NIL population was 0.61 in the spring and 0.63 in the autumn infected with Pss4, and 0.32 in the spring and 0.20 in the autumn inoculated with Pss1632, suggesting that resistance to the phylotype II strain was mainly affected by non-genetic effects, especially temperature, in contrast to phylotype I. It was also found that the phenotypic coefficient of variation for Pss1632 had two-fold higher values than the genetic coefficient of variation in both seasons. Both QTLs Bwr-6 and Bwr-12 contributed 54\% for Pss4, but only 19\% for Pss 1632 of the phenotypic effect on the resistance. Thus it is suggested that there are additional genetic factors playing a role on the resistance, which might have been lost during backcrossing. The minor QTLs on chromosome 5 detected by $\mathrm{R} / \mathrm{qtl}$ is a candidate for explaining this effect. Consistent with previous studies, major genes have been identified on chromosome 6 and 12. The new information of the current work is the fine mapping of specific Bwr-6 sites conferring resistance to Pss1632 and Pss4. Resistance to Pss1632 was mapped to an interval of 2.7 cM between 6_35, 736,000 _SLM6-110 to 6_35,949,000_SLM6-107 SNP marker, while resistance to Pss4 with a low LOD value $(<3.0)$ was associated with a $5.0 \mathrm{cM}$ interval between 6_33,444,000_SLM6-47 and 6_33,868,000_SLM6-124. Bwr12 had a significant effect, LOD scores of 5.8-16.1 $(P<0.01)$ to control BW disease caused by the Pss4 strain was confirmed to be located in $\sim 30 \mathrm{cM}$ wide interval ranged from 12_1,981,000_SLM12-54 to 12_4,209,000_SLM12-69 marker in the NIL population. The NIL population was designed to fine-map $B w r-6$ and not $B w r-12$, therefore the Bwr-12 interval remained very large in this population. Previous reports showed that Bwr-12 is confined to phylotype I defense reponse [29, 36-37]. Recently it was reported by Kim et al., [65] that genes encoding leucine-rich repeat (LRR) receptor-like proteins are located in the Bwr-12 region and may be associated with resistance.

\section{Materials and Methods}

\subsection{Confirmation of Bwr-12 and Bwr-6 in $\mathrm{H7996}$}

Bwr-12 and Bwr-6 was confirmed in the 188 F9 RILs developed from the cross between 'Hawaii 7996' (H7996, resistant, S. lycopersicum) and 'West Virginia 700' (WVa700, susceptible, S. pimpinellifolium) (HW), the same population previously used to map Bwr-12 and Bwr-6 [37]. The RILs had been evaluated in ten greenhouse or field trials, including five countries (Taiwan, Thailand, the Philippines, Indonesia and Reunion), six locations (World Vegetable Center (WorldVeg) and Taichung in Taiwan; Chiangmai in Thailand; UPLB in the Philippines; Purwakara in Indonesia; CIRAD in Reunion) and against eight pathogen strains (Pss4, Pss186, TC, Tm151, CM, PW, JT516 and JT519) (Table 8). The genetic parameters (estimates of phenotypic variation, coefficient of variation, genotypic and phenotypic coefficients of variation, broad sense heritability, and genetic advance) for bacterial wilt incidence in RIL population in various environments were estimated according to the methods suggested by previous reports [66-68] after analysis of variance by means of $R$ package 'Ime4'. All strains used in phenotyping were classified as race 1-phylotype I except for JT516, which was race 3-phylotype II. DNA of 188 F9 RILs and parents was provided by the Bacteriology Unit of WorldVeg and used for GBS after quantification using a spectrophotometer (Beckman coulter, DU 800, Krefeld, Germany) and integrity check on $1 \%$ agarose gels. Genomic DNA from $\mathrm{BC}_{3} \mathrm{~F}_{3}$ NIL plants including parents and controls was extracted from young leaves using DNeasy Plant Mini Kit (Qiagen Inc., Hilden, Germany) in 2016-2017.

\subsubsection{Genotyping by Sequencing (GBS)}

Genomic DNA from 95 F9 RILs H7996 x WVa700 representing the resistance spectrum of the population and from parental plants was submitted to GBS analysis. Sequencing library preparation was done as described by Elshire et al. [42] and SE sequencing was performed on two lanes of an Illumina Hi-seq 2500 (Illumina Inc.) at the Genomics Core Facility, Biodiversity Research Center, Academia Sinica, Taiwan. FASTQ files for $100 \mathrm{bp}$ single reads were analyzed using the Tassel5 GBS v2 Pipeline [69]. Quality trimming was conducted using the GBSSeqToTag- DBPlugin with the following parameters: kmerLength 93, minKmerL 20, mnQS 20 and mxKmer- Num 108. The 
alignment to the reference sequence of $S$. lycopersicum (ftp://ftp.solgenomics.net/ tomato genome/assembly/build_2.40) was done using the BWA aligner with $n=3$ maxSeedDiff as the parameter for maximal sequence differences. The SAMToGBSdbPlugin was applied to determine the positions of tags on the reference genome by setting the parameters aProp to 0.05 and aLen to 70 . SNPs were identified in the aligned tags by the DiscoverySNPCallerPlugin with 0.6 and 0.1 for minimum locus coverage and minimum minor allele frequency, respectively. The SNP data set was obtained by sequential application of the following three plugins: SNPQualityProfilterPlugin for quality control, UpdateSNPPositionQualityPlugin for verifying debugging SNPs/tags position with false for deleteOldData, and ProductionSNPCallerPluginV2 for the final SNP calling with kmerLength 93. The F9 lines were highly homozygous (93.97\%) and heterozygous loci were changed to missing data. SNPs were filtered by setting 165 for minimum count out of 190 sequences with minimum and maximum frequency as 0.02 and 0.99 , respectively.

Table 8. Descriptive statistics for bacterial wilt incidence in the H7996 $\times$ WVa700 RIL population, parents and susceptible control evaluated in various environments.

\begin{tabular}{|c|c|c|c|c|c|c|c|c|c|c|c|}
\hline Plant & Variables & $\begin{array}{l}\text { ID- } \\
\text { PW }^{\text {a }}\end{array}$ & $\begin{array}{c}\text { PH- } \\
\text { Tm151 }\end{array}$ & $\begin{array}{c}\text { RE- } \\
\text { JT516 }\end{array}$ & $\begin{array}{c}\text { RE- } \\
\text { JT519 }\end{array}$ & $\begin{array}{l}\mathrm{TH}- \\
\mathrm{CM}\end{array}$ & $\begin{array}{c}\text { TW- } \\
\text { Pss186 }\end{array}$ & $\begin{array}{l}\text { TW- } \\
\text { Pss4a }\end{array}$ & $\begin{array}{l}\text { TW- } \\
\text { Pss4b }\end{array}$ & $\begin{array}{l}\text { TW- } \\
\text { Pss4c }\end{array}$ & $\begin{array}{c}\text { TW - } \\
\text { TC }\end{array}$ \\
\hline \multirow[t]{5}{*}{ RIL } & Mean & 66.7 & 83.3 & 76.4 & 20.6 & 41.3 & 56.7 & 80.4 & 70.4 & 52.0 & 56.7 \\
\hline & Minimum & 0 & 12.5 & 20.0 & 0 & 0 & 0 & 12.5 & 6.3 & 0 & 0 \\
\hline & Median & 82.5 & 90.6 & 75.0 & 7.5 & 31.3 & 56.3 & 87.5 & 81.3 & 56.3 & 31.1 \\
\hline & Maximum & 100 & 100 & 100 & 87.5 & 100 & 100 & 100 & 100 & 100 & 100 \\
\hline & $\begin{array}{l}\text { Standard } \\
\text { deviation }\end{array}$ & 34.8 & 22.8 & 18.5 & 23.2 & 35.3 & 24.7 & 22.6 & 27.7 & 28.3 & 34.4 \\
\hline H7996 & Mean & 0 & 18.8 & 19.9 & 0 & 0 & 4.2 & 24.0 & 19.8 & 12.5 & 15.0 \\
\hline WVa700 & Mean & 100 & 100 & 89.2 & 79.7 & 100 & 86.5 & 99.0 & 96.9 & 56.3 & 100 \\
\hline L390 & Mean & 100 & 100 & n.d. & n.d. & 100 & 100 & 100 & 100 & 81.3 & 100 \\
\hline
\end{tabular}

a Trial code is named as A - B, with ' $\mathrm{A}$ ' the country abbreviation and ' $\mathrm{B}$ ' strain code: ID - PW (Purwakarta, Indonesia in 2004 - Race 1, biovar 3), PH - Tm151 (Institute of Plant Breeding, University of Philipines Los Baños in 2000- Tomato, race 1, biovar 3), RE - JT516 (Centre de cooperation international en recherche' agronomique pour le de'veloppement (CIRAD) in 2003 - Potato, race 3, biovar 2, phylotype II), RE - JT519 (CIRAD, Reunion in 2003 - Geranium, race 1, biovar 3, phylotype I), TH - CM (Chiangmai, Thailand in 2004 - Race, biovar 3), TW - Pss186 (The World Vegetable Center (Worldveg), Taiwan in 2004 - Tomato, race 1, biovar 4, phylotype I), TW - Pss4a (Greenhouse, Worldveg, Taiwan in 2003 - Tomato, race 1, biovar 3, phylotype I), TW - Pss4b (Screenhouse, Worldveg, Taiwan in 2003- Tomato, race 1, biovar 3, phylotype I), TW - Pss4c (Colonization, Worldveg, Taiwan in 2006 - Tomato, race 1, biovar 3, phylotype I), TW - TC (Taichung, Taiwan in 2004 - Tomato, race 1 , biovar 4 , phylotype I).

\subsubsection{Linkage Map Construction and QTL Mapping}

A linkage map for HW was constructed in two steps using JoinMap 4.0 [70] with a minimum LODscore of 3.0 in the maximum likelihood mode. First, a preliminary linkage map was constructed with 2,951 polymorphic SNP markers obtained from GBS. Among the SNPs belonging to 13 genetic LG obtained from first map construction, a total of 1,347 redundant SNP markers co-localizing with other markers were removed. Finally, 1,604 markers including SSR and CAPS/ dCAPS obtained from genomic sequences of anchored BAC clones in tomato [71-72] and SNP markers of this study, respectively were genetically mapped to 12 chromosomes. The 28 and 23 SSR markers located in Bwr6 and Bwr-12, respectively [37], were added for linkage analysis and map construction. When several markers co-localized at a locus, only one of these markers was considered. Segregation distortion of individual markers was calculated by Chi-square test in JoinMap. QTLs were detected using composite interval mapping (CIM) in QGene 4.0 [73] with stepwise cofactor selection and a scanning interval of $0.2 \mathrm{Mb}$ for physical mapping and $2 \mathrm{cM}$ for genetic mapping. Significance thresholds for $\mathrm{p}$ $<0.05$ and 0.01 of LOD (logarithm of odds) values were estimated by permutation tests. The proportion of phenotypic variation and additive effects of the each QTL were obtained from CIM analysis. Data analysis was repeated using the R/qtl package and reference genome of 
S_lycopersicum_chromosomes.2.4 as well as 3.0 to confirm the presence of QTL and their interaction [74].

\subsubsection{CAPS Marker Design}

The SNP markers associated to BW resistance QTLs were converted to PCR-based CAPS or dCAPS markers using CAPS Designer (https://solgenomics.net/tools/caps_designer/caps_input.pl), SNP2CAPS (http://pgrc.ipk-gatersleben.de/snp2caps/) [75] and dCAPS Finder 2.0 (http://helix.wustl. edu/dcaps/dcaps.html) [76] (Table 9). Primer design and quality check was conducted by primer3 0.4.0 (http://bioinfo.ut.ee/primer3-0.4.0/primer3) and PCR Primer Stats (http://www.bioinformatics. org/sms2/pcr_primer_stats.html ), respectively. The PCR mixture for CAPS amplification contained $40 \mathrm{ng}$ plant genomic DNA, $0.25 \mu \mathrm{M}$ of each forward and reverse primers, $200 \mu \mathrm{M}$ dNTPs (FOcusBio, P-2.5M), 10× Supertherm GOLD buffer with $15 \mathrm{mM} \mathrm{MgCl}_{2}$ (Bersing, JMR-470), and $0.125 \mathrm{U}$ of Supertherm GOLD Taq (hot start) polymerase (Bersing, JMR-851, Taiwan) in a total volume of $10 \mu \mathrm{L}$. Template DNA was initially denatured at $95^{\circ} \mathrm{C}$ for $10 \mathrm{~min}$, then 35 cycles for PCR amplification, using the following conditions: denaturation at $95^{\circ} \mathrm{C}$ for $30 \mathrm{~s}$, annealing at 50,55, or $60^{\circ} \mathrm{C}$ depending on the primer for $45 \mathrm{~s}$, extension at $72^{\circ} \mathrm{C}$ for $45 \mathrm{~s}$, and then final extension at $72^{\circ} \mathrm{C}$ for $5 \mathrm{~min}$. The reaction mixture for the enzyme digestion contained: $2 \mu \mathrm{L}$ PCR product, $7 \mu \mathrm{L}$ ddH2O, and $0.3 \mu \mathrm{L}$ restriction enzyme $(10 \mathrm{U} / \mu \mathrm{L})$, and incubation was done according to the instructions of the supplier for 14-16 $\mathrm{h}$. Twelve CAPS/dCAPS markers were subsequently tested in the RIL parents, NIL parents, and 20 $\mathrm{BC}_{3} \mathrm{~F}_{3} \mathrm{NIL}$ lines. The enzyme-digested products were visualized after electrophoresis on $1 \%$ agarose gels.

Table 9. List of CAPS/dCAPS markers used in the study.

\begin{tabular}{|c|c|c|c|c|c|c|c|c|}
\hline Primer & $\mathrm{Chr}$ & $\mathrm{MP}(\mathrm{bp})$ & Sequence & $\begin{array}{l}\text { AS } \\
\text { (bp) }\end{array}$ & $\mathrm{Tm}$ & RE & $\begin{array}{l}\mathrm{Tr} \\
\left({ }^{\circ} \mathrm{C}\right)\end{array}$ & $\begin{array}{c}\text { Fragment } \\
\text { (bp) }\end{array}$ \\
\hline \multirow[t]{2}{*}{ HW06-355 } & 6 & 14058992 & CGTGAAGCGAAGTAATCACG & 118 & 60 & Hpy188I & 37 & $80,38,118$ \\
\hline & & & GCATCGTGGGGTCAATTTC & & & & & \\
\hline \multirow[t]{2}{*}{ HW06-577 } & 6 & 34026861 & GCTCCTTTAATGGGACATTC & 115 & 60 & MluCI & 37 & $5,47,63,68$ \\
\hline & & & GATGGGGGCAATAGCTCAG & & & & & \\
\hline \multirow[t]{2}{*}{ HW06-580 } & 6 & 34422554 & AGCAACAATCGAAAGCCAAG & 115 & 60 & ScaI & 37 & $25,90,115$ \\
\hline & & & TCATGCTGCTTGCAATGTTT & & & & & \\
\hline \multirow[t]{2}{*}{ HW06-591 } & 6 & 34577936 & GGGTAGCTTTCTCCCAATCT & 96 & 60 & MspI & 37 & $32,64,96$ \\
\hline & & & ATTCAAGCTGCTCGGAACAC & & & & & \\
\hline \multirow[t]{2}{*}{ HW06-604 } & 6 & 35273098 & CTGCCGTGATACTCTCTCCA & 115 & 60 & BstUI & 60 & $28,87,115$ \\
\hline & & & CAGAGGATATGTCGCCAAGG & & & & & \\
\hline \multirow[t]{2}{*}{ HW06-633 } & 6 & 37029305 & TAGATTTCCGCTGCTGATTT & 99 & 60 & AluI & 37 & $22,77,99$ \\
\hline & & & ACTTTTCATCAAACAGATCC & & & & & \\
\hline \multirow[t]{2}{*}{ HW12-015 } & 12 & 2337422 & CAGCAACGATGTCTATTTGG & 85 & 55 & AluI & 37 & $35,50,85$ \\
\hline & & & CGATGTATGAACTCTGAAGATTACC & & & & & \\
\hline \multirow[t]{2}{*}{ HW12-016 } & 12 & 2510564 & CAAAGCAACCTGCCTCTCGT & 98 & 57 & HindIII & 37 & $20,78,98$ \\
\hline & & & CAGGAAGCAGCACGAAAGCT & & & & & \\
\hline \multirow[t]{2}{*}{ HW12-020 } & 12 & 2735144 & CAGCTAGTTGAAGTTTCATTTCC & 131 & 55 & BsmI & 65 & $46,85,131$ \\
\hline & & & ССТTTCTTСАССАСТGATTT & & & & & \\
\hline \multirow[t]{2}{*}{ HW12-023 } & 12 & 2817063 & TTGTGTTTCTAAGCGCTGGCT & 89 & 55 & BspMI & 37 & $31,58,89$ \\
\hline & & & CGTCATTTAGATTGTTATAGCAC & & & & & \\
\hline \multirow[t]{2}{*}{ HW12-031 } & 12 & 3134873 & ССТССТСAAATGAGAACACACA & 92 & 57 & BsmAI & 55 & 32,60 \\
\hline & & & CAGCAACAGACAAAGTGTTC & & & BcoDI & 37 & 92 \\
\hline
\end{tabular}

Chr, chromosome; MP, map position; AS, amplicon size; Length of the amplicon; Tm, melting temperature; RE, restriction enzyme; $\mathrm{Ti}$, incubating temperature. Candidate CAPS sequences were targeted by 11 restriction 
endonucleases (RE): Alu, BcoDI, BsmAI, BsmI, BspMI, BstUI, HindIII, Hpy188I, MluCI, MspI, ScaI (New England BioLabs Inc., Massachusetts, USA) and selected based on location of RE cutting site, and resolution ratio.

\subsection{Fine-mapping and Validation of Bwr-12 and Bwr-6 in the NIL Population}

To reduce the Bwr-6 QTL interval size and to validate the effects of resistance alleles at major QTLs identified in the RILs against phylotype I and phylotype II strains, backcrosses were carried out between the BW resistant F9 RIL NHG41 as donor line and the recurrent susceptible parent BL1413. Over all the backcross and selfing generations during NIL production, eight SSR markers (six for Bwr-6 and two for Bwr-12) from Wang et al. (2013) and four SNP markers designed from limited resequencing experiments of the QTL-6 interval in NHG41 and BL1413 were used for marker-assisted foreground selection. At each backcross generation, all progenies were genotyped to select plants carrying different fragments of Bwr-6 in absence or presence of Bwr-12. In addition, the backcrossed plants were screened with 24 background markers for maximal reconstitution of the recurrent BL1413 genotype. $76 \mathrm{BC}_{3} \mathrm{~F}_{1}$ progenies were then self-pollinated and a total of $156 \mathrm{BC}_{3} \mathrm{~F}_{2}$ progenies were screened for homozygous insertions of Bwr-6 fragments, followed by a second generation of selfpollination. $\mathrm{BC}_{3} \mathrm{~F}_{3}$ lines carrying diverse fragments of $\mathrm{Bwr}-6$ at homozygote state were selected. Out of the $145 \mathrm{BC}_{3} \mathrm{~F}_{3}$ NILs, 80 NILs with various marker Bwr-6 fragments at the QTL region were used for genotyping and phenotyping.

\subsubsection{Phenotyping for Disease Resistance in the NIL Population}

The NIL population was assessed for BW resistance at WorldVeg Taiwan using two pathogen strains, Pss4 (race 1-phylotype I) and Pss1632 (race 3-phylotype II). Entries were arranged in a random complete block design with three replications and six plants per replication in a plastic house at WorldVeg during (1) the cooler spring season from Mar. 1 through Apr. 11 (17.7-24.7 ${ }^{\circ} \mathrm{C}$ ) and (2) the warmer autumn season from Sep. 19 through Oct. 31 (21.3-29. $\left.8^{\circ} \mathrm{C}\right)$ in 2017, respectively. Both parental lines, WorldVeg lines CLN2026D and CLN2585D, susceptible checks WVa700, L390 and CLN286, and resistant checks H7996, CRA66 and L285 were included in each replication. Three to six seeds of each genotype were sown in plastic pots $(8 \mathrm{~cm}$ diameter $)$ which were placed in plastic containers $\left(34 \times 50 \mathrm{~cm}^{2}\right)$ holding 24 pots arranged in four rows and six columns. Among germinated seedlings in a pot, the healthiest plant was left for artificial inoculation and the others were roughed around two weeks after sowing. Approximately four-week-old plants were inoculated by drenching $30 \mathrm{ml}$ bacterial suspension $\left(10^{8} \mathrm{CFU} / \mathrm{ml}\right)$ on the soil surface near the base of each plant. A wilting score was recorded once a week for four weeks on a scale of 0 to 5 , where $0=$ no visible wilt, $1=$ one leaf wilted, $2=$ two or three leaves wilted, $3=$ all except top leaves wilted, $4=$ all leaves wilted, and $5=$ dead [36]. Percentage of wilted plant $(W)$ was calculated as described by Winstead and Kelman [77] and Mohamed et al. [78] using the formula $W=[(\mathrm{Nt}-\mathrm{Nh}) / \mathrm{Nt}] \times 100$, where $\mathrm{Nt}$ is number of total plants and $\mathrm{Nh}$ is number of unwilted plants. W was arcsine square root-transformed for data normalization before QTL analysis using the PROC MIXED procedure of SAS (SAS 9.2, SAS Institute, Cary, USA)

\subsubsection{SSR and CAPS/dCAPS genotyping}

To verify the QTL effect against race 1-phylotype I Pss4 and race 3-phylotype II Pss1632 strains and to narrow down the Bwr-6 interval, totally 34 SSR [37] and CAPS/dCAPS markers located on chromosome 6 (17 markers) and 12 (17 markers) were used for genotyping. PCR reactions were carried out as described above and the PCR products were visualized on $6 \%$ acrylamide gels. Ten $\mu \mathrm{L}$ of the PCR product was mixed with $5 \mu \mathrm{L}$ of the loading dye. Out of the $15 \mu \mathrm{L}, 2$ and 3-4 $\mu \mathrm{L}$ were loaded on the gel and run for 50 and $25 \mathrm{~min}$ for SSR and CAPS/dCAPS genotyping at 160V, respectively.

\subsection{Statistical Analyses}


R software was utilized to perform statistical analyses for analysis of variance (ANOVA), Duncan's multiple range test (DMRT), single marker analysis (SMA) and correlation analysis. Broad-sense heritability for each season and each strain was calculated as described by Allard [67].

Author Contributions: conceptualization, I.S. Shin and R. Schafleitner; genotyping and QTL mapping, J.C. Hsu and S.M. Huang; resistance assay for RIL, J.F. Wang and NIL, J.R. Chen; data analysis, I.S. Shin and J.F. Wang; writing-original draft preparation, I.S. Shin; writing-review and editing, J.F. Wang, P. Hanson and R. Schafleitner

Acknowledgments: This study was supported by the Rural Administration Development of Korea Rep. (10000279-01) and the Council of Agriculture of Taiwan (10000299-01). The works were performed at the World Vegetable Center. The core donors to the World Vegetable Center are the Republic of China (Taiwan), UK Department for International Development (UK/DFID), United States Agency for International Development (USAID), Australian Centre for International Agricultural Research (ACIAR) Germany, Thailand, Philippines, Korea, and Japan. The authors gratefully thank Burlakoti Pragyan for technical assistance and Chiou Fen Hsu for resistance assay on NIL population.

Conflicts of Interest: The authors declare no conflict of interest.

$\begin{array}{ll}\text { Abbreviations } \\ \text { SNP } & \text { Single-nucleotide polymorphism } \\ \text { QTL } & \text { Quantitative trait loci } \\ \text { GBS } & \text { Genotype-by-sequencing } \\ \text { RIL } & \text { Recombinant inbred line } \\ \text { NIL } & \text { Near isogenic line } \\ \text { LOD } & \text { Logarithm of odds } \\ \text { SSR } & \text { Simple sequence repeat } \\ \text { (d)CAPS } & \text { (derived) Cleaved amplified polymorphic sequences } \\ \text { NGS } & \text { Next-generation sequencing } \\ \text { SDR } & \text { Segregation distortion rate } \\ \text { PVE } & \text { phenotypic variation explained } \\ \text { CIM } & \text { composite interval mapping }\end{array}$

\section{References}

1. Daunay, M.C.; Laterrot, H.; Scott, J.W.; Hanson, P.; Wang, J.F. Tomato resistance to bacterial wilt caused by Ralstonia solanaearum E.F. Smith: ancestry and peculiarities. TGC Report 2010, 60, 6-40.

2. Hayward, A.C. Biology and epidemiology of bacterial wilt caused by Pseudomonas Solanacearum. Annual Rev. Phytopathol. 1991, 29, 65-87.

3. Huerta, A.I.; Milling, A.; Allen, C. Tropical Strains of Ralstonia solanacearum outcompete race 3 biovar 2 strains at lowland tropical temperatures. Appl. Environ. Microbiol. 2015, 81, 3542-3551.

4. Kelman, A. The bacterial wilt caused by Pseudomonas solanacearum. A literature review and bibliography. North Carolina Agricultural Experiment Station Tech Bul. 1953, N99, 194.

5. Wang, J.F.; Hanson, P.M.; Barens, J.A. Worldwide evaluation of international set of resistance sources to bacterial wilt in tomato. In: Prior P, Allen C, Elphinstone J (eds) Bacterial Wilt disease: Molecular and Ecological Aspects, Springer, Berlin, 1998; pp. 269-275.

6. Denny, T.P. Plant pathogenic Ralstonia species. In: Gnanamanickam SS (ed) Plant-Associated Bacteria, Springer Publishing, Dordrecht, 2006; pp 573-644.

7. Elphinstone, J.G. The current bacterial wilt situation: a global overview. In: Allen, C.; Prior, P.; Hayward, A.C. (eds) Bacterial Wilt Disease and the Ralstonia solanacearum Species Complex, American Phytopathological Society Press, St. Paul, MN, 2005; pp 9-28.

8. Krausz, J.P.; Thurston, H.D. Breakdown of resistance to Pseudomonas solanacearum in tomato. Phytopathology 1975, 65, 1272-1274.

9. Messiaen, C.M. (1989) Environmental influences on the severity of tomato bacterial wilt in the French West Indies: Interactions with varietal resistance. In: Tomato and Pepper Production in the Tropics. Proceed. International Symposium on Integrated Management Practices; Green, S.K. (Sc. Ed.); Griggs, T.D.; McLean, B.T. (Publ. Eds), AVRDC, Shanhua, Taiwan. 1989; pp 235-238. 
10. Buddenhagen, I.; Kelman, A. Biological and physiological aspects of bacterial wilt caused by Pseudomonas solanacearum. Annu. Rev. Phytopathol. 1964, 2, 203-230.

11. Fegan, M.; Prior, P. How complex is the Ralstonia solanacearum species complex"'. In: Allen, C.; Prior, P.; Hayward, A.C. (eds) Bacterial Wilt: The Disease and Ralstonia solanacearum Species Complex, APS Press, St Paul, MN, 2005; pp 449-461.

12. Poussier, S.; Prior, P.; Luisetti, J.; Hayward, A.C.; Fegan, M. Partial sequencing of the hrpB and endoglucanase genes confirms and expands the known diversity within the Ralstonia solanacearum species complex. Syst. Appl. Microbiol. 2000, 23, 479-486.

13. Prior, P.; Fegan, M. Recent development in the phylogeny and classification of Ralstonia solanacearum. In: Momol, T.; Jones, J.B. (eds) Proceedings of the first international symposium on tomato diseases. ISHSActa Horticulturae, 2005; pp 127-136.

14. Wicker, E.; Lefeuvre, P.; Cambiaire, J.C.; Lemaire, C.; Poussier, S.; Prior, P. Contrasting recombination patterns and demographic histories of the plant pathogen Ralstonia solanacearum inferred from MLSA. ISME J 2012, 6, 961-974.

15. Mansfield, J.; Genin, S.; Magori, S.; Citovsky, V.; Sriariyanum, M.; Ronald, P.; Dow, M.; Verdier, V.; Beer, S.V.; Machado, M.A.; Toth, I.; Salmond, G.; Foster, G.D. Top 10 plant pathogenic bacteria in molecular plant pathology, Mol. Plant Pathol. 2012, 13, 614-629.

16. Gaelle, H. Breeding for resistances to Ralstonia solanacearum. Front. Plant Sci. 2014, 5, 715. doi:10.3389/fpls. 2014.00715

17. Genin, S. Molecular traits controlling host range and adaptation to plants in Ralstonia solanacearum. New Phytol. 2010, 187, 920-928.

18. Hanson, P.M.; Wang, J.; Licardo, O.; Haudin, M.S.; Hartman, G.L.; Lin, Y.; Chen, J. Variable reaction of tomato lines to bacterial wilt evaluated at several locations in southeast Asia. HortSci. 1996, 31, 143-146.

19. Lopes, C.A.; Quezado-Soares, A.M.; Melo, P.E.D. Differential resistance of tomato cultigens to biovar I and III of Pseudomonas solanacearum. Plant Dis. 1994, 78, 320-327.

20. Peter, K.V.; Gopalakrishnan, T.R.; Rajan, S.; Sadhan, K.P.G. Breeding for resistance to bacterial wilt in tomato, eggplant and pepper. In: Bacterial wilt. ACIAR proceedings No. 45, edited by Hartman, G.L.; Hayward, A.C. ACIAR, Canberra. 1993; pp 183-190.

21. Prior, P.; Steva, H.; Cadet, P. Aggressiveness of strains of Pseudomonas solanacearum from the French West Indies on tomato. Plant Dis. 1990, 74, 962-965.

22. Prior, P.; Grimault, V.; Schmit, J. Resistance to bacterial wilt (Pseudomonas solanacearum) in tomato: present status and prospects. In: Bacterial Wilt, the disease and its causative agent Pseudomonas solanacearum, Hayward, A.C.; Hartman, G.L. (eds.), Wallingford (UK), CAB International : 1994; pp 209-223.

23. Carmeille, A.; Prior, P.; Kodja, H.; Chiroleu, F.; Luisetti, J.; Besse, P. Evaluation of resistance to race 3, biovar 2 of Ralstonia solanacearum in tomato germplasm. J. Phytopathol. 2006, 154, 398-402.

24. Hai, T.T.H.; Esch, E.; Wang, J.F. Resistance to Taiwanese race 1 strains of Ralstonia solanacearum in wild tomato germplasm. European J. Plant Pathology 2008, 122, 471-479.

25. Jaunet, T.X.; Wang, J.F. Variation in genotype and aggressiveness of Ralstonia solanacearum race 1 isolated from tomato in Taiwan. Phytopathology 1999, 89, 320-327.

26. Kim, S.G.; Hur, O.S.; Ro, N.Y.; Ko, H.C.; Rhee, J.H.; Sung, J.S.; Ryu, K.Y.; Lee, S.Y.; Baek, H.J. Evaluation of resistance to Ralstonia solanacearum in tomato genetic resources at seedling stage. Plant Pathol. J. 2016, $32,58-64$.

27. Scott, J.W.; Wang, J.W.; Hanson, P.M. Breeding tomatoes for resistance to bacterial wilt, a global view. Acta Hort. 2005, 695, 161-172.

28. Ashrafi, H.; Kinkade, M.; Foolad, M.R. A new genetic linkage map of tomato based on a Solanum lycopersicum $\times$ S. pimpinellifolium RIL population displaying locations of candidate pathogen response genes. Genome 2009, 52, 935-956.

29. Carmeille, A.; Caranta, C.; Dintinger, J.; Prior, P.; Luisetti, J.; Besse, P. Identification of QTLs for Ralstonia solanacearum race 3-phylotype II resistance in tomato. Theor. Appl. Genet. 2006, 113, 110-121.

30. Danesh, D.; Aarons, S.; McGill, G.E.; Young, N.D. Genetic dissection of oligogenic resistance to bacterial wilt in tomato. Mol. Plant Microbe Interact. 1994, 7, 464-471.

31. Mangin, B.; Thoquet, P.; Olivier, J.; Grimsley, N.H. Temporal and multiple quantitative trait loci analyses of resistance to bacterial wilt in tomato permit the resolution of linked loci. Genetics 1999, 151, 1165-1172.

32. Miao, L.; Shou, S.; Cai, J.; Jiang, F.; Zhu, Z.; Li, H. Identification of two AFLP markers linked to bacterial wilt resistance in tomato and conversion to SCAR markers. Mol. Biol. Rep. 2009, 36, 479-486. 
33. Thoquet, P.; Olivier, J.; Sperisen, C.; Rogowsky, P.; Laterrot, H.; Grimsley, N. Quantitative trait loci determining resistance to bacterial wilt in tomato cultivar Hawaii7996. Mol. Plant-Microbe Interact. 1996, 9, 826-836.

34. Thoquet, P.; Olivier, J.; Sperisen, C.; Rogowsky, P.; Prior, P.; Anais, G.; Mangin, B.; Bazin, B.; Nazer, R.; Grimsley, N. Polygenic resistance of tomato plants to bacterial wilt in the French West Indies. Mol. PlantMicrobe Interact. 1996, 9, 837-842.

35. Truong, H.T.H.; Kim, S.Y.; Tran, H.N.; Nguyen, T.T.T.; Nguyen, L.T.; Hoang, T.K. Development of a SCAR marker linked to bacterial wilt (Ralstonia solanacearum) resistance in tomato line Hawaii 7996 using bulked-segregant analysis. Hortic. Environ. Biotechnol. 2015, 56, 506-515.

36. Wang, J.F.; Olivier, J.; Thoquet, P.; Mangin, B.; Sauviac, L.; Grimsley, N.H. Resistance of tomato line Hawaii7996 to Ralstonia solanacearum Pss4 in Taiwan is controlled mainly by a major strain-specific locus. Mol. Plant-Microbe Interact. 2000, 13, 6-13.

37. Wang, J.F.; Ho, F.I.; Truong, H.T.H.; Hugan, S.M.; Balatero, C.H.; Dittapongpitch, V.; Hidayati, N. Identification of major QTLs associated with stable resistance of tomato cultivar 'Hawaii 7996' to Ralstonia solanacearum. Euphytica 2013, 190, 241-252.

38. Young, N.D.; Danesh, D. Understanding bacterial wilt resistance in tomato through the use of DNA genetic-markers. Bact. Wilt 1994, 145-155.

39. Collard, B.C.; Mackill, D.J. Marker-assisted selection: an approach for precision plant breeding in the twenty-first century. Philos. Trans. R. Soc. Lond. B. Biol. Sci. 2008, 363, 557-572.

40. Foolad, M.R. Genome mapping and molecular breeding of tomato. Int. J. Plant Genomics 2007 doi:10.1155/2007/64358.

41. Feuillet, C.; Leach, J.E.; Rogers, J.; Schnable, P.S.; Eversole, K. Crop genome sequencing: lessons and rationales. Trends Plant Sci. 2011, 16, 77-88.

42. Elshire, R.J.; Glaubitz, J.C.; Sun, Q.; Poland, J.A.; Kawamoto, K.; Buckler, E.S.; Mitchell, S.E. A robust, simple genotyping-by-sequencing (GBS) approach for high diversity species. PLoS One 2011, 6, e19379.

43. Fu, Y.B.; Peterson, G.W. Genetic diversity analysis with 454 pyrosequencing and genomic reduction confirmed the eastern and western division in the cultivated barley gene pool. Plant Genome 2011, 4, 226 237.

44. Poland, J.; Endelman, J.; Dawson, J.; Rutkoski, J.; Wu, S.; Manes, Y.; Dreisigacker, S.; Crossa, J.; SánchezVilleda, H.; Sorrells, M.; Jannink, J.L. Genomic selection in wheat breeding using genotyping-bysequencing. Plant Genome. 2012, 5, 103-113.

45. Beissinger, T.M.; Hirsch, C.N.; Sekhon, R.S.; Foerster, J.M.; Johnson, J.M.; Muttoni, G.; Vaillancourt, B.; Buell, C.R.; Kaeppler, S.M.; Leon, N. Marker density and read depth for genotyping populations using genotyping-by-sequencing. Genetics 2013, 193, 1073-1081.

46. Spindel, J.; Wright, M.; Chen, C.; Cobb, J.; Gage, J.; Harrington, S.; Lorieux, M.; Ahmadi, N.; McCouch, S. Bridging the genotyping gap: using genotyping by sequencing (GBS) to add high-density SNP markers and new value to traditional bi-parental mapping and breeding populations. Theor. Appl. Genet. 2013, 126, 2699-2716.

47. Capel, C.; Fernández del Carmen, A.; Alba, J.M.; Lima-Silva, V.; Hernández-Gras, F.; Salinas, M.; Boronat, A.; Angosto, T.; Botella, M.A.; Fernández-Muñoz, R.; Granell, A.; Capel, J.; Lozano, R. Wide-genome QTL mapping of fruit quality traits in a tomato RIL population derived from the wild-relative species Solanum pimpinellifolium L. Theor. Appl. Genet. 2015, 128, 2019-2035.

48. Celik, I.; Gurbuz, N.; Uncu, A.T.; Frary, A.; Doganlar, S. Genome-wide SNP discovery and QTL mapping for fruit quality traits in inbred backcross lines (IBLs) of Solanum pimpinellifolium using genotyping by sequencing. BMC Genomics 2017, 18:1. https://doi.org/10.1186/s12864-016-3406-7.

49. Marrano, A.; Birolo, G.; Prazzoli, M.L.; Lorenzi, S.; Valle, G.; Grando, M.S. SNP-discovery by RADsequencing in a germplasm collection of wild and cultivated grapevines (V. vinifera L.). PLoS One 2017, e0170655.

50. Berthouly-Salazar, C.; Mariac, C.; Couderc, M.; Pouzadoux, J.; Floc'h, J.B.; Vigouroux, Y. Genotyping-bysequencing SNP Identification for crops without a reference genome: Using transcriptome based mapping as an alternative strategy. Front. Plant Sci. 2016. 7, 777.

51. Gurgul, A.; Miksza-Cybulska, A.; Szmatola, T.; Jasielczuk, I.; Piestrzynska-Kajtoch, A.; Fornal, A.; SemikGurgul, E.; Bugno-Poniewierska, M. Genotyping-by-sequencing performance in selected livestock species. Genomics 2018, https://doi.org/10.1016/j.ygeno.2018.02.002.

52. Hospital, F. Challenges for effective marker-assisted selection in plants. Genetica 2009, 136, 303-310. 
53. Hospital, F. Selection in backcross programmes. Philos. Trans. R. Soc. B. Biol. Sci. 2005, 360, $1503-1511$.

54. Kinkade, M.P.; Foolad, M.R. Validation and fine mapping of lyc12.1, a QTL for increased tomato fruit lycopene content. Theor. Appl. Genet. 2013, 126, 2163-2175.

55. Kongprakhon, P.; Cuesta-Marcos, A.; Hayes, P.M.; Richardson, K.L.; Sirithunya, P.; Sato, K.; Steffenson, B.; Toojinda, T. Validation of rice blast resistance genes in barley using a QTL mapping population and near-isolines. Breeding Sci. 2009, 59, 341-349.

56. Lavaud, C.; Boutet, G.; Moussart, A.; Poncet, C. Validation of QTL for resistance to Aphanomyces euteiches in different pea genetic backgrounds using near-isogenic lines. Theor. Appl. Genet. 2015, 128, 2273-2288.

57. Lin, C.H.; Wang, J.F.; Wu, Y.F.; Cheng, A.H. Phylotype II race 3 biovar 2 strain of Ralstonia solanacearum in Taiwan: survival potential and virulence on tomato, eggplant, and pepper. Acta horticulturae 2015, 1069, 293-300.

58. Gabriel, D.W.; Allen, C.; Schell, M.; Denny, T.P.; Greenberg, J.T.; Duan, Y.P.; Flores-Cruz, Z.; Huang, Q.; Clifford, J.M.; Presting, G.; González, E.T.; Reddy, J.; Elphinstone, J.; Swanson, J.; Yao, J.; Mulholland, V.; Liu, L.; Farmerie, W.; Patnaikuni, M.; Balogh, B.; Norman, D.; Alvarez, A.; Castillo, J.A.; Jones, J.; Saddler, G.; Walunas, T.; Zhukov. A.; Mikhailova, N. Identification of open reading frames unique to a select agent: Ralstonia solanacearum Race 3 Biovar 2. Mol. Plant-Microbe Interact. 2006, 19, 69-79.

59. Milling, A.; Babujee, L.; Allen, C. Ralstonia solanacearum extracellular polysaccharide is a specific elicitor of defense responses in wilt-resistant tomato plants. PLoS One 2011, 6, e15853.

60. Menna, A.; Nguyen, D.; Guttman, D.S.; Desveaux, D. Elevated temperature differentially influences effector-triggered immunity outputs in Arabidopsis. Front. Plant Sci. 2015, 6, 995.

61. Wang, Y.; Bao, Z.; Zhu, Y.; Hua, J. Analysis of temperature modulation of plant defense against biotrophic microbes. Mol. Plant Microbe Interact. 2009, 22, 498-506.

62. Ciampi, L.; Sequeira, L.; French, E.R. Latent infection of potato tubers by Pseudomonas solanacearum. Am. Potato J. 1980, 57, 377-386.

63. Ciampi, L.; Sequeira, L. Influence of temperature on virulence of Race 3 strains of Pseudomonas solanacearum. Am. Potato J. 1980, 57, 307-317.

64. Kim, B.; Hwang, I.S.; Lee, H.J.; Lee, J.M.; Seo, E.; Choi, D.; Oh, C.S. Identification of a molecular marker tightly linked to bacterial wilt resistance in tomato by genome-wide SNP analysis. Theor. Appl. Genet. 2018, http://doi.org/10.1007/s00122-018-3054-1

65. Burton, G.W.; de Vane, E.H. Estimating heritability in tall fescue (Festuca arundinacea) from replicated clonal material. Agron. J. 1953, 45, 478-481.

66. Allard, R.W. Principles of plant breeding. John Wiley and Sons Inc., New York, USA., ISBN13:9780471023159, 1960; p 254.

67. Johnson, H.W.; Suleiman, T.M.; Lusas, E.W. Estimates of genetic and environmental variability in soybeans. Agron. J. 1955, 47, 314-318.

68. Glaubitz, J.; Casstevens, T.; Lu, F., Harriman, J.; Elshire R.J.; Sun, Q.; Edward, S. TASSEL-GBS: A high capacity genotyping by sequencing analysis pipeline. PLoS One 2014, 9, e90346.

69. Van Ooijen, J.W. Multipoint maximum likelihood mapping in a full-sib family of an outbreeding species. Genetic Res. 2011, 93, 343-349.

70. Geethanjali, S.; Chen, K.Y.; Pastrana, D.V.; Wang, J.F. Development and characterization of tomato SSR markers from genomic sequences of anchored BAC clones on chromosome 6. Euphytica 2010, 173, 85-97.

71. Geethanjali, S.; Kadirvel, P.; Pena, R.; Rao, E.S.; Wang, J.F. Development of tomato SSR markers from anchored BAC clones of chromosome 12 and their application for genetic diversity analysis and linkage mapping. Euphytica 2011, 178, 283-295.

72. Joehanes, R.; Nelson, J.C. QGene 4.0 an extensible Java QTL-analysis platform. Bioinformatics 2008, 24, 2788-2789.

73. Broman, K.W.; Saunak, S.; A guide to QTL mapping with R/qtl. Springer, USA, 2009

74. Thiel. T.; Kota, R.; Grosse, I.; Stein, N.; Graner, A. SNP2CAPS: a SNP and INDEL analysis tool for CAPS marker development. Nucleic Acids Res. 2004, 32, e5

75. Neff, M.M.; Turk, E.; Kalishman, M. Web-based primer design for single nucleotide polymorphism analysis. Trends Genetics 2002, 18, 613-615.

76. Winstead, N.N.; Kelman, A. Inoculation techniques for evaluating resistance to Pseudomonas solanacearum. Phytopathology 1952, 42, 628-634.

77. Mohamed, A.A.S.; Kamal, A.M.A.; Kenawy, M.A.; Farag, A.S. First report of bacterial wilt caused by Ralstonia solanacearum biovar 2 race 1 on tomato in Egypt. Plant Pathol. J. 2014, 30, 299-303. 
